\title{
The Orb6-Sts5 Axis Regulates Stress Granule Formation and Heat Stress Response in Fission Yeast
}

Robert N. Tams ${ }^{1 *}$, Chuan Chen ${ }^{1 *}$, Illyce Nuñez ${ }^{1}$, Patrick Roman Haller ${ }^{1}$, Fulvia Verde ${ }^{1 * *}$

Author Affiliations: ${ }^{1}$ Department of Molecular and Cellular Pharmacology, University of Miami, Miami, FL. ${ }^{*}$ These authors contributed equally to experiments performed in this work.

${ }^{* *}$ Correspondence:

Dr. Fulvia Verde

Associate Professor of Molecular and Cellular Pharmacology

University of Miami

Miami, FL 33136

305-243-3106

Email: fverde@miami.edu

Running Head: Orb6-Sts5 Regulates Stress Granules

Key Words: P-Bodies, Stress Granules, Orb6, Sts5, Heat Stress

Abbreviations: Processing Bodies, P-Bodies; RNA Binding Protein, RBP; Ribonucleoprotein RNP; Nuclear Dbf2 Related, NDR; Guanine Nucleotide Exchange Factor, GEF; Intrinsically Disordered Domain, IDD.

Character Count: 19,999 
Running Head: Orb6-Sts5 Regulates Stress Granules

\begin{abstract}
:
The NDR/LATS family kinases are a subclass of the AGC serine/threonine kinases which are important for morphogenesis and cell growth control. Using the model organism Schizosaccharomyces pombe, we previously reported that the NDR/LATS kinase Orb6 phosphorylates the RNA-binding protein (RBP) Sts5 serine 86 residue on its Intrinsically Disordered Domain (IDD). When dephosphorylated, Sts5 forms ribonucleoprotein (RNP) granules that colocalize with processing bodies (P-Bodies) and translationally repress mRNAs important for polarized cell growth. Here we report that Sts5 puncta colocalize with both PBodies and stress granules (SG) in response to glucose starvation, as well as heat, oxidative, and hyperosmotic stress. We find that loss of Sts 5 decreases the number of stress granules, indicating that Sts 5 has a role in promoting stress granule formation. Conversely, inhibition of Orb6 kinase promotes Sts 5 aggregation and stress granule formation. In addition, loss of Sts 5 decreases cell survival after heat stress, whereas decreasing Orb6 protein levels or including the sts5S86A mutation, which promotes Sts5 aggregation, leads to increased survival. These data indicate that the Orb6-Sts 5 axis is not only important for regulation of polarized growth but also for response to environmental stress, as dysregulation of the Orb6-Sts5 axis affects stress granule formation and cell survival.
\end{abstract}

\title{
Introduction:
}

Nuclear Dbf2-related (NDR) kinases are highly conserved members of the AGC protein kinase family which regulate essential cellular processes including morphogenesis, growth and proliferation, mitosis, and apoptosis (Verde et al., 1995; Verde et al., 1998; Hergovich et al., 2006; Hergovich et al., 2007; Vichalkovski et al., 2008; Chiba et al., 2009; Hergovich et al., 2009; Cornils et al., 2011; Yang et al., 2014). Several studies have implicated dysregulation of NDR kinases in the development of cancer, and NDR also plays a role in neuronal differentiation (Millward et al., 1998; Hauschild et al., 1999; Ross et al., 2000; Adeyinka et al., 2002; Cornils et al., 2010; Napoletano et al., 2011; Zhang et al., 2015). Given the role of these proteins in the development of disease, it is crucial to identify the substrates of NDR kinases, and to elucidate their underlying mechanisms of action. The fission yeast Schizosaccharomyces pombe is a robust model for the study of cell morphogenesis and growth due to its well-defined cylindrical shape and growth pattern, which can be easily quantified (Mitchison and Nurse, 1985). Since NDR kinases are highly 
Running Head: Orb6-Sts5 Regulates Stress Granules

conserved amongst yeast and humans, S. pombe is an ideal system to elucidate the targets and mechanism of action of NDR kinases (Verde et al., 1995; Verde et al., 1998; Hou et al., 2003; Hergovich et al., 2006; Das et al., 2009; Das et al., 2015; Nunez et al., 2016; Chen et al., 2019; Tay et al., 2019).

S. pombe has a NDR/LATS kinase known as Orb6, which is responsible for regulation of polarized cell growth (Verde et al., 1995). We previously demonstrated that Orb6 governs cell polarity by spatially regulating the conserved GTPase Cdc42 via phosphorylation of the guanine nucleotide exchange factor Gef1 (Das et al., 2009; Das et al., 2012; Das et al., 2015). More recently, we found a novel and genetically separable function of Orb6 in promoting polarized cell growth by spatiotemporal regulation of RNA-binding protein Sts5 (Nunez et al., 2016; Chen et al., 2019). Sts5 is an RNA binding protein (RBP) homologous to human Dis3L2, which is associated with Perlman's syndrome and Wilm's tumor in humans (Toda et al., 1996; Jansen et al., 2009; Kurischko et al., 2011; Astuti et al., 2012; Vaggi et al., 2012; Malecki et al., 2013; Lv et al., 2015; Robinson et al., 2015). Sts5 functions to repress translation of specific mRNAs, many of which encode proteins involved in polarized cell growth, via binding and sequestration into ribonucleoprotein (RNP) granules (Nunez et al., 2016). This process is mediated by the Sts5 intrinsically disordered domain (IDD), which is responsible for aggregation of the Sts5 protein and coalescence into RNP granules, under conditions of nutritional stress (Nunez et al., 2016; Chen et al., 2019). However, under conditions favorable to growth, Orb6 kinase inhibits Sts 5 puncta formation via phosphorylation of Sts 5 at serine 86, promoting Sts5 physical association with the 14-3-3 protein Rad24 (Chen et al., 2019). Rad24 binding represses formation of Sts 5 puncta, thus promoting translation of Sts 5 bound mRNAs (Nunez et al., 2016). Environmental stress such as nitrogen starvation, or crowded growth conditions leading to stationary phase, inhibit Orb6 kinase activity, which results in the translational repression of mRNAs involved in polarized growth via formation of Sts5 puncta (Nunez et al., 2016; Chen et al., 2019).

Consistent with the function of Sts 5 in translational regulation, Orb6 inhibition causes Sts 5 puncta to partially co-localize with processing bodies (P-Bodies) (Nunez et al., 2016). P-Bodies are evolutionarily conserved cytoplasmic ribonucleoprotein (RNP) granules enriched in RNA decay machinery that control mRNA localization and stability (Ingelfinger et al., 2002; van Dijk et al., 2002; Wang et al., 2002; Sakuno et al., 2004). During nitrogen or glucose deprivation, Sts 5 proteins assemble into puncta that partially colocalize with the P-Body marker Dcp1-mCherry (Nilsson and Sunnerhagen, 2011; Nunez et al., 2016; Chen 
Running Head: Orb6-Sts5 Regulates Stress Granules

et al., 2019). In this paper, we report that other environmental stressors such as osmotic stress, oxidative stress, and heat stress, also promote Sts 5 coalescence into RNP granules. We find that under these stress conditions Sts5 granules colocalize with stress granules, another type of mRNA containing cytoplasmic aggregate which forms in response to translational repression and contain the stress granule-specific marker Pabp1/Pab1 (Nilsson and Sunnerhagen, 2011). Consistent with these findings, loss of Sts5 decreases, whereas Orb6 kinase inhibition increases, stress granule formation and resilience to heat stress. Thus, the Orb6-Sts5 regulatory axis modulates the formation of stress granules, and also cell survival in response to heat stress.

\section{Results and Discussion:}

Sts5 Puncta Co-Localize with Both P-Bodies and Stress Granules in Response to Oxidative, Osmotic, and Heat Stress

We previously demonstrated that Sts5 partially co-localizes with P-Bodies following Orb6 inhibition, or in media lacking glucose or nitrogen (Nunez et al., 2016). Other stresses, such as osmotic stress, oxidative stress, and heat stress, are also known to induce the formation of P-Bodies (Nilsson and Sunnerhagen, 2011). To determine if Sts5 would co-localize with P-Bodies when cells are exposed to these stressors, log phase sts5-3xGFP dcp1-mCherry cells were exposed to either oxidative, osmotic, or heat stress, and Sts5 puncta and P-Body formation was assessed with microscopy. In untreated control cells, Sts5-3xGFP remains diffuse in the cytoplasm with few puncta observed, and P-Bodies form at low numbers, as visualized by the P-Body marker Dcp1-mCherry (Figure 1, a-c). However, for cells exposed to $10 \mathrm{mM} \mathrm{H}_{2} \mathrm{O}_{2}$, Sts5 puncta form and co-localize with P-Bodies (Figure 1, d-f). This result was also observed for cells exposed to $1 \mathrm{M} \mathrm{NaCl}$ for 30 minutes (Figure $1, \mathrm{~g}-\mathrm{i}$ ), or to $42^{\circ} \mathrm{C}$ heat for 20 minutes (Figure $1, \mathrm{j}-\mathrm{I}$ ).

Both P-Bodies and RNA binding proteins are thought to promote the assembly of another type of cytoplasmic ribonucleoprotein granules known as stress granules (Buchan et al., 2008; Wheeler et al., 2016), which have been closely associated with cancer for their role in stress adaptation, and also with neurodegenerative diseases due to their ability to undergo phase transitions into biomolecular condensates (Gilks et al., 2004; Ramaswami et al., 2013; Anderson et al., 2015; Aguzzi and Altmeyer, 2016). Stress granules are membrane-less organelles, which are often spatially associated with and contain many of the 
Running Head: Orb6-Sts5 Regulates Stress Granules

same classes of proteins as P-Bodies, such as RNA binding proteins (reviewed in (Buchan and Parker, 2009; Guzikowski et al., 2019)). The proteomes of stress granules and P-Bodies generally have little overlap in S. cerevisiae (Guzikowski et al., 2019), and stress granules may include components not found in P-Bodies such as translation initiation factors and translationally stalled mRNAs (Anderson and Kedersha, 2009; Buchan and Parker, 2009; Poblete-Duran et al., 2016). However, there are still a number of proteins that are common to both types of RNP granules, and it has been suggested that transfer of components can occur between P-Bodies and stress granules during docking events (Kedersha et al., 2005; Stoecklin and Kedersha, 2013). Given this relationship, and since stress granules are often associated with mRNA binding proteins (Jain et al., 2016), it is plausible that Sts5 puncta are also associated with stress granules.

To determine if Sts 5 co-localizes with stress granules, the poly(A)-binding protein marker Pabp1DsRed was used to visualize stress granules in the Sts5-3xGFP background under conditions of glucose limitation, which is known to induce formation of both stress granules and Sts5 puncta (Nilsson and Sunnerhagen, 2011; Nunez et al., 2016). sts5-3xGFP pabp1-DsRed cells were suspended in EMM medium with or without $2 \%$ glucose for 20 minutes. In glucose rich medium, both the Sts5-3xGFP and Pabp1-DsRed markers were observed as mostly diffuse within the cytoplasm with the formation of very few puncta (Figure 2A, a-c). In contrast, Sts5 puncta were clearly observed following glucose starvation, and these puncta partially co-localize with stress granules (Figure 2A, d-f).

Since Sts 5 was found to coalesce into cytoplasmic puncta in response to oxidative stress, osmotic stress, or heat stress (Figure 1), and because stress granules are known to form under these conditions (Mahboubi and Stochaj, 2017; Guzikowski et al., 2019), we tested if Sts5 co-localizes with stress granules following these additional stress types. sts5-3xGFP pabp1-DsRed cells were exposed to oxidative stress (Figure 2B, d-f), hyperosmotic stress (Figure 2B, g-i), or heat stress (Figure 2B, j-I), and found that Sts5 puncta readily associate with stress granules, whereas Sts5 puncta and stress granules do not assemble in untreated controls (Figure 2B, a-c).

To further support these findings, we investigated the localization of ssp1 mRNA, which encodes a CamK kinase (Matsusaka et al., 1995; Hanyu et al., 2009). ssp1 is a Sts5-bound mRNA which co-localizes with P-Bodies and is translationally repressed upon formation of Sts5 puncta (Nunez et al., 2016). Thus, we performed RNA-FISH analysis to localize ssp1 RNA in sts5-3xGFP pabp1-DsRed cells cultured in EMM 
Running Head: Orb6-Sts5 Regulates Stress Granules

medium with or without glucose. We observed co-localization of Sts5 puncta, ssp1 mRNA, and stress granules in cells cultured in medium lacking glucose (Figure 2C, a-d). Conversely, for cells in glucose-rich medium, these factors displayed a diffuse localization (data not shown)(Nunez et al., 2016).

These findings indicate that, in addition to responding to nutritional cues such as glucose or nitrogen starvation (Nunez et al., 2016; Chen et al., 2019), Sts5 also assembles into cytoplasmic RNP granules in response to more diverse environmental stressors such as oxidative stress, osmotic stress, and heat stress (Figures 1, 2A, 2B). In addition, Sts5 puncta associate with both P-Bodies and stress granules under these diverse stress conditions (Figures 1, 2A, 2B). One reversible function of stress granules is to alter the translational landscape of the cell by decreasing specific mRNA availability for translation, such as ssp1 mRNA (Figure 2C) (Buchan and Parker, 2009). Consistent with this idea, we previously found that the Ssp1 protein levels drastically increase upon heat stress, when sts5 is deleted (Nuñez et al, 2016).

\section{Sts5 Promotes Stress Granule Assembly}

While it is known that stress granules initially assemble through a process known as liquid-liquid phase separation (Aguzzi and Altmeyer, 2016), much remains to be elucidated regarding the mechanisms and factors involved in their formation (Nilsson and Sunnerhagen, 2011; Nunez et al., 2016). Coalescence of RBPs into puncta is thought to promote nucleation of both P-Bodies and stress granules (Brangwynne et al., 2009; Kato et al., 2012; Brangwynne, 2013; Lee et al., 2013; Hyman et al., 2014; Becker and Gitler, 2015; Elbaum-Garfinkle et al., 2015; Kroschwald et al., 2015; Lin et al., 2015; Patel et al., 2015). Formation of these RBP "seeds" is often regulated by post-translational modification (such as citrullination, methylation, and notably, phosphorylation) of an intrinsically disordered domain which controls RBP self-aggregation (Hofweber and Dormann, 2019; Owen and Shewmaker, 2019). Sts5 contains an intrinsically disordered domain, which is phosphorylated by Orb6 kinase at serine 86 (Chen et al., 2019). We have previously demonstrated that Orb6 inhibition promotes the formation of P-Bodies upon glucose deprivation in a Sts5 dependent manner (Nunez et al., 2016). This suggests that Sts 5 aggregates may serve as a nucleation site for P-Body formation. Since Sts5 also co-localizes with stress granules following stress (Figures 2A, 2B), we wanted to determine whether Sts 5 plays a role in seeding stress granules. 
Running Head: Orb6-Sts5 Regulates Stress Granules

To evaluate this possibility, we followed the formation of stress granules in the sts $5 \Delta$ mutant using the stress granule marker Pabp1-DsRed. In media containing glucose, Pabp1-DsRed was largely diffuse within the cytoplasm in both the sts $5 \Delta$ and control strains (Figure 3A; a, c). However, after culturing cells for 20 minutes in media lacking glucose, the number of stress granules was decreased by $44 \%$ for the sts $5 \Delta$ mutant as compared to the control (Figure $3 A$, b, d; Figure $3 B,{ }^{* * *} p<0.001$, unpaired t-test).

Since Orb6 regulates Sts5 coalescence, we also created an orb6-as2 pabp1-DsRed strain (which expresses a chemically inhibitable allele of orb6) to determine if inhibition of Orb6 kinase could drive stress granule formation. orb6-as2 pabp1-DsRed cells were treated with 1-NA-PP1 inhibitor and monitored for the formation of stress granules over a three-hour time course. We found that inhibition of Orb6-as 2 at $25^{\circ} \mathrm{C}$ does not induce the formation of stress granules (Figure 3C; a, c), These findings indicate that Orb6 kinase inhibition alone is not sufficient to induce stress granule formation, while it is sufficient to promote P-Body formation, as we previously reported (Nunez et al., 2016). However, when 1-NA-PP1 treated cells were subsequently heat shocked for 20 minutes at $42^{\circ} \mathrm{C}$, we observed a remarkable increase in the number of stress granules, as compared to the heat-shocked DMSO control (Figure 3C; b, d). The number of stress granules formed was quantified for three independent experiments ( $\mathrm{N}=90$ cells/condition), and the number of stress granules increased, on average, by $54 \%$ for the 1-NA-PP1 treated cells as compared to the heat shocked DMSO control (Figure 3D; ${ }^{* * *} \mathrm{p}<0.001$, unpaired t-test).

Overall, these data indicate that the presence of Sts5 is important for the formation of stress granules, and that Orb6 kinase plays a role in this process by modulating the extent of Sts5 granule formation. Since Orb6 kinase inhibition alone is not sufficient to drive stress granule formation, it is likely that additional factor(s) play a role in driving Sts5-mediated stress granule formation. For example, other factors such as the vigilin homologue Vgl1 (Wen et al., 2010), signaling factors such as calcineurin (Higa et al., 2015), and protein kinase C Pck2 (Kanda et al., 2021) also associate with stress granules in response to thermal stress, and stress granule formation is also stimulated in response to heat stress by the RNAbinding protein Nrd1 (Satoh et al., 2012). Additionally, the intrinsically disordered N-terminus of Sts5 is phosphorylated on multiple residues, suggesting it is the target of additional protein kinases (Magliozzi et al., 2020). 
Running Head: Orb6-Sts5 Regulates Stress Granules

\section{Sts5 Activity Modulates Heat Resilience in S. pombe}

Stress granules provide a mechanism whereby cells can rapidly adapt to environmental stressors by immediately and reversibly halting translation of specific mRNAs (Mahboubi and Stochaj, 2017). These condensates can aid in protection from specific stress, such as viral infection (Miller, 2011; Onomoto et al., 2014) or modulate susceptibility to heat stress (Kroschwald and Alberti, 2017; Riback et al., 2017). Since Sts5 responds to heat, oxidative, and osmotic stress by co-localizing with both stress granules and PBodies (Figures 1,2) and is important for stress granule formation (Figure 3, A-B), we hypothesized that modulating the assembly of Sts5 into RNP granules plays a role in cell protection from stress. Thus, we tested how loss of Sts5 (sts5 4 ), or the sts5S86A mutation that causes increased Sts5 puncta formation (Chen et al., 2019), affect cell survival following exposure to stress. To test this, wild-type, sts5 $\Delta$, sts5-HA, and sts5S86A-HA strains were diluted to an equivalent optical density, exposed to a $48^{\circ} \mathrm{C}$ heat shock for 20 minutes, and survival was determined by plating cells to calculate CFUs/mL as percent survival compared to untreated control strains. Following heat shock, the sts5 $\Delta$ strain exhibited a decrease in survival (-0.92-fold) as compared to the wild-type control (Figure 4A; ${ }^{*} p<0.001$, One-Way ANOVA with Tukey's test). Conversely, the sts5S86A-HA mutant exhibited an increase in survival as compared either the wild-type (2.5-fold) or sts5-HA controls (2.88-fold) (Figure 4A; ${ }^{* * *} p<0.001$, One-Way ANOVA with Tukey's test). The sts5-HA strain exhibited similar survival as compared to the wild type, as expected.

To further investigate the impact of Sts5 modulation on heat tolerance (exposure to heat for extended times), wild-type, sts5 $\Delta$, sts5-HA, and sts5S86A-HA log-phase cells were diluted to an equivalent optical density and split into sample sets that were incubated for 6 hours at either $25^{\circ} \mathrm{C}$ or restrictive temperature $\left(36.5^{\circ} \mathrm{C}\right)$ in a shaking incubator. Following incubation, cells were serially diluted and plated, and plates were incubated at $25^{\circ} \mathrm{C}$. CFU's $/ \mathrm{mL}$ were calculated as a relative percent survival for samples exposed to $36.5^{\circ} \mathrm{C}$ compared to untreated controls for each strain (Figure 4B). Again, it was found that the sts $5 \Delta$ strain exhibited decreased survival compared to wild type, whereas the hypermorphic sts $5 S 86 A-H A$ strain displayed increased survival, as compared to the sts5-HA control (Figure 4B; ${ }^{* * *} p<0.001$, One-Way ANOVA with Tukey's post hoc test).

Thus, our data indicate that Sts 5 coalescence is important for survival and heat stress resilience following various durations and intensities of exposure to elevated temperatures. Therefore, we determined 
Running Head: Orb6-Sts5 Regulates Stress Granules

whether Sts 5 granule assembly is modulated by increased temperature and whether the sts 5 S $86 \mathrm{~A}$ mutation increases formation of Sts5 puncta following exposure to heat. To do this, sts5-3xYFP and sts5S86A$3 x Y F P$ strains were cultured at $29^{\circ} \mathrm{C}, 32^{\circ} \mathrm{C}, 35.5^{\circ} \mathrm{C}$, or $42^{\circ} \mathrm{C}$ for 30 minutes, while control sts $5-3 x Y F P$ and sts5S86A-3xYFP cells were maintained at $25^{\circ} \mathrm{C}$ throughout the experiment. Following heat stress, microscopy was performed and the number of Sts 5 puncta were counted at each temperature. The sts5$3 x Y F P$ control began to form visible puncta only at $35.5^{\circ} \mathrm{C}$ (Figure $4 \mathrm{C}$; a-e), whereas the sts5S86A-3xYFP mutant began to form puncta already at $25^{\circ} \mathrm{C}$ (Figure $\left.4 \mathrm{C}, \mathrm{f}-\mathrm{j}\right)$. These differences were statistically significant (Figure 4D; One way ANOVA with Tukey's post hoc test, ${ }^{* * *} p<0.001,{ }^{* *} p<0.01$ ), and Sts5S86A predisposition to the formation of puncta was readily apparent until the temperature reached $42^{\circ} \mathrm{C}$ at which point the control formed approximately the same number of puncta.

Our findings indicate an important role for serine 86 phosphorylation in modulating the extent of Sts5 puncta assembly in response to increased temperatures (Figure 4, C-D). Since Orb6 kinase phosphorylates serine 86 (Chen et al., 2019), we tested if downregulation of Orb6 kinase also increases cell resilience to heat stress. To transcriptionally repress Orb6, a thiamine-repressible orb6-as2 strain was used. Log phase wild-type and orb6-as2 cells were pre-cultured with or without $15 \mu \mathrm{M}$ thiamine for 16 hours at $32^{\circ} \mathrm{C}$. Samples were diluted to an equivalent optical density and were heat shocked at $48^{\circ} \mathrm{C}$ for 15 minutes while control samples were maintained at $32^{\circ} \mathrm{C}$. Following heat shock, cells were plated on media lacking thiamine, and CFU's/mL were calculated as described previously. The orb6-as2 strain, when precultured in the presence of thiamine, exhibited a striking 17.09-fold increase in survival following heat shock compared to the untreated control (Figure 4E; One-Way ANOVA and Tukey's test, ${ }^{* * *} p<0.001$ ). This striking increase in resilience was readily observed on Petri plates (Supplemental Figure 1) and was notably higher than the relative increase in heat resilience observed for the sts5S86A mutant (Figure 4, A-B). Overall, these data indicate that the Orb6 kinase modulates stress granule assembly and resilience to heat stress, in part, by phosphorylating mRNA binding protein Sts5 on serine 87 (see model, Figure 5).

Since stress granules are important for responding to stress (Mahboubi and Stochaj, 2017), our findings suggest that the loss of Sts 5 decreases cell survival by decreasing stress granule formation. Additionally, since Sts5 is important for translational regulation of Sts5-bound mRNA (Nunez et al., 2016), it is plausible that decreased survival for sts $5 \Delta$ is due to changes in the translational landscape of the cell. 
Running Head: Orb6-Sts5 Regulates Stress Granules

Consistent with this idea, the sts5S86A mutant, which is predisposed to forming Sts5 puncta (Figure 4, CD), exhibits increased resilience to heat stress (Figure 4, A-B). Inhibition of Orb6, which also induces Sts5 coalescence (Nunez et al., 2016; Chen et al., 2019), drastically increases resilience to heat stress (Figure $4 \mathrm{E})$. Since this increase is much greater for Orb6 inhibition than for the Sts5S86A mutation, it is likely that Orb6 has additional roles in resilience which are independent of Sts5.

We previously showed that Orb6 kinase activity is decreased during nutritional deprivation, a stressful condition leading to cellular quiescence and dormancy (Chen et al., 2019). Additionally, we found that either Orb6 kinase repression or sts5S86A mutation promotes extended chronological lifespan (Chen et al., 2019). In fungi, dormancy is associated with a solidification of the cytoplasm (Munder et al., 2016), and increased resilience to stress. For example, in the budding yeast Saccharomyces cerevisiae, cellular quiescence, when induced by limiting nitrogen, glucose, or phosphate, promotes resilience to heat stress (Klosinska et al., 2011). Therefore, it is possible that the Orb6-Sts5 axis modulates stress response by regulating the assembly of different types of RNP granules, and thus fostering cell resilience during dormancy. These findings provide insight into the formation and differential regulation of RNP granules, which play an important role in human disease, as aberrant cytoplasmic condensates are associated with cancer, neurodegeneration, and infectious diseases (Alberti and Dormann, 2019). Furthermore, our findings highlight a novel role for NDR kinase in the control of RNP phase separation and suggest that Orb6 kinase may have a fundamental role in promoting biophysical changes in the cell cytoplasm.

\section{Materials and Methods:}

\section{Strains and Growth Medium}

Schizosaccharomyces pombe strains used in this study were derived from wild-type strains 972 or 975 and are displayed in Supplemental Table 1. S. pombe was maintained in yeast extract plus supplements (YES) or Edinburgh minimal medium supplemented with $0.5 \%$ ammonium chloride (EMM) and additional supplements as needed (Histidine, Leucine, Adenine, or Uracil) at a concentration of $225 \mathrm{mg} / \mathrm{L}$. All strains were cultured at $25^{\circ} \mathrm{C}$ unless otherwise noted. Liquid cultures were incubated at 180 RPM in a shaking incubator, and all cultures were diluted daily such that they were maintained in logarithmic growth for a minimum of 8 generations prior to performing experiments. 
Running Head: Orb6-Sts5 Regulates Stress Granules

Mating of yeast was performed on sporulation agar (SPA) medium at $25^{\circ} \mathrm{C}$. Following digestion with glusulase (PerkenElmer, NEE-154001EA), colonies were selected using pombe minimal glutamate (PMG) medium containing necessary supplements and $100 \mu \mathrm{g} / \mathrm{mL}$ Natamycin or $150 \mu \mathrm{g} / \mathrm{mL}$ G418 as needed.

\section{Microscopy}

For experiments utilizing microscopy, samples were imaged with an Olympus BX61 fluorescent microscope using appropriate filters (GFP, YFP, or Cy3). Exposure times range from 2000-2500ms for each experiment and remain consistent among all samples for that experiment. All images are deconvolved projections from 12 Z-stacks separated by a step size of $0.3 \mu \mathrm{M}(\mathrm{Bar}=5 \mu \mathrm{M})$ that were produced with SlideBook software (Intelligent Imaging Innovations; Denver, CO) and subsequently exported to ImageJ v1.53a for analysis (Schneider et al., 2012).

\section{RNP Granule Induction}

To determine localization of Sts 5 puncta relative to P-Bodies, we previously constructed a sts5-3xGFP dcp1-mCherry (FV2267) strain (Nunez et al., 2016). sts5-3xGFP dcp1-mCherry was cultured in YES and diluted to O.D.595nm $=0.1$ and cells were allowed to grow at this O.D.595nm for a minimum of 1 hour. Samples were pelleted and resuspended in YES containing either $10 \mathrm{mM} \mathrm{H}_{2} \mathrm{O}_{2}$ for 1 hour, $1 \mathrm{M} \mathrm{NaCl}$ for 30 minutes, or heat shocked at $42^{\circ} \mathrm{C}$ for 20 minutes. Control samples were resuspended in YES only. To determine localization of Sts 5 puncta relative to stress granules, we introduced the marker Pabp1-DsRed, constructing a sts5-3xGFP pabp1-DsRed strain (FV2361). We tested the localization of Sts5 relative to stress granules under the same conditions described above (heat, hyperosmotic, and oxidative stress). To test the effects of glucose limitation, cells were grown in minimal medium (EMM) containing $2 \%$ glucose for at least 8 generations, and then were centrifuged, washed with the appropriate medium, and resuspended either in EMM lacking glucose or in EMM with $2 \%$ glucose. Images are representative of samples from three independent experiments. 
Running Head: Orb6-Sts5 Regulates Stress Granules

\section{RNA Fluorescent In Situ Hybridization (RNA FISH)}

Localization of ssp1 mRNA was determined using RNA-FISH as previously described, with modifications according to Nunez et al. (Brengues and Parker, 2007; Nilsson and Sunnerhagen, 2011; Heinrich et al., 2013; Nunez et al., 2016). sts5-3xGFP pabp1-DsRed cells (FV2361) were cultured in EMM lacking glucose for 20 minutes prior to fixation and hybridization of RNA was performed with 20-mer DNA oligonucleotides (Stellaris) labeled with Quasar 705 fluorochromes (Bar $=5 \mu \mathrm{m})$.

\section{Glucose Starvation and Orb6 Inhibition Assays}

To determine if Sts5 was required for the formation of stress granules, a glucose starvation assay was performed with sts5+ pabp1-DsRed (FV1684) and sts5s pabp1-DsRed (FV3192) mutants. Samples were cultured to log phase in minimal medium (EMM) and were washed once with $5 \mathrm{~mL}$ minimal medium lacking glucose. Cells were then resuspended in $5 \mathrm{~mL}$ minimal medium lacking glucose and were incubated at $25^{\circ} \mathrm{C}$ and $180 \mathrm{RPM}$ in a shaking incubator for 20 minutes. Following incubation, $1 \mathrm{~mL}$ aliquots were centrifuged at 4000 RPM for 1 minute and resuspended in a small amount of residual medium. Microscopy was performed as previously described and the number of stress granules was manually counted. This experiment was performed in triplicate, and $\mathrm{N}=90$ cells per strain per strain per condition in total.

For Orb6 inhibition assays, orb6-as2 pabp1-DsRed (FV3226) and pabp1-DsRed control (FV1684) strains were cultured to log phase in minimal medium containing adenine. 1-NA-PP1 was added to samples at a final concentration of $50 \mu \mathrm{M}$, and microscopy was performed as previously described for time-points of $30 \mathrm{~m}, 1$ hour, 2 hours, and 3 hours post addition of inhibitor. For assays in which Orb6 was inhibited and then cells were heat shocked, 1-NA-PP1 was added to cells 15 minutes prior to heat shock, whereas DMSO was added for control cells. Samples were then shifted to a $42^{\circ} \mathrm{C}$ shaking water bath incubator for 20 minutes. Additional controls were maintained at $25^{\circ} \mathrm{C}$. Microscopy was performed as previously described and stress granules were manually counted. This experiment was performed in triplicate, and $\mathrm{N}=90$ cells per strain per condition in total.

\section{Heat Shock Survival Assay}

Wild-type (FV2644), sts5s (FV2674), sts5-HA (FV2645), and sts5S86A-HA (FV2649) strains were cultured 
Running Head: Orb6-Sts5 Regulates Stress Granules

in EMM and maintained in log-phase for a minimum of eight generations. Each strain was diluted to O.D. $595 \mathrm{~nm}=0.2$ (approximately $4 \times 10^{6}$ cells $/ \mathrm{mL}$ ) in $5 \mathrm{~mL}$ EMM and allowed to grow at this density for one hour at $25^{\circ} \mathrm{C}$ shaking at $180 \mathrm{RPM}$. Samples were either maintained at $25^{\circ} \mathrm{C}$ or heat shocked at $48^{\circ} \mathrm{C}$ for 20 minutes. Following heat shock, experimental and control samples were each serially diluted, plated in triplicate on EMM plates, and incubated at $25^{\circ} \mathrm{C}$ for approximately 72 hours. Colony forming units per $\mathrm{mL}$ (CFU's/mL) were calculated for each condition, and percent survival was calculated by dividing CFU's/mL for heat shocked replicates by their respective average untreated control CFU's $/ \mathrm{mL}$. This experiment was performed in biological triplicate, and data was normalized to the average wild-type percent survival for each independent experiment. Following normalization, data from independent experiments was combined, and a one-way ANOVA with Tukey's post hoc test was performed to determine statistical significance $(\alpha=$ 0.05). To determine the impact of intermediate to long-term restrictive temperature on these strains, this experiment was repeated with modifications. In this case, samples were incubated at $25^{\circ} \mathrm{C}$ or $36.5^{\circ} \mathrm{C}$ for 6 hours. Following incubation, cells were serially diluted and plated in triplicate, and incubated at $25^{\circ} \mathrm{C}$ for approximately 72 hours. Calculation of CFU's $/ \mathrm{mL}$ and normalization of data was performed as previously described, and this experiment was performed in biological triplicate.

For heat shock survival analysis of the orb6-as2 strain (FV2527) and its respective wild-type control (FV2530), cells were initially pre-cultured in minimal medium supplemented with adenine at 180 RPM and $32^{\circ} \mathrm{C}$. In order to repress the expression of orb6-as2 the culture was split into two sets, either with or without thiamine at a final concentration of $15 \mu \mathrm{M}$ and was allowed to grow for $\sim 16$ hours. Cells were diluted to an equivalent O.D.595nm of $0.2\left(4 \times 10^{6} \mathrm{cells} / \mathrm{mL}\right)$ in appropriate media, and cells were allowed to grow for an additional 2 hours. Samples were then heat shocked in a $48^{\circ} \mathrm{C}$ shaking water bath for 15 minutes while controls were maintained at $32^{\circ} \mathrm{C}$. All samples were then serially diluted and plated on minimal medium supplemented with adenine, but lacking thiamine, for subsequent quantification of CFU's $/ \mathrm{mL}$ as previously described.

\section{Temperature Dependent Analysis of Sts5 Puncta}

sts5-3xYFP (FV2518) and sts5S86A-3xYFP (FV2522) strains were used to determine whether Sts5 puncta are induced at lower temperatures when Sts 5 is hyperactive as compared to a wild-type allele. Each strain 
Running Head: Orb6-Sts5 Regulates Stress Granules

was cultured to log-phase in EMM, diluted to O.D.595nm= 0.1 , and cells were allowed to grow for a minimum of 1 hour at $25^{\circ} \mathrm{C}$. Aliquots of each strain were created, and samples were heat shocked at $29^{\circ} \mathrm{C}, 32^{\circ} \mathrm{C}$, $35.5^{\circ} \mathrm{C}$, or $42^{\circ} \mathrm{C}$ for 30 minutes. Control cells were maintained at $25^{\circ} \mathrm{C}$ throughout the experiment. Following exposure to heat shock, samples were imaged using an Olympus BX61 microscope. To determine differences in number of puncta, 20 cells per strain were manually scored for Sts5 (YFP) puncta at each temperature. This experiment was replicated independently in triplicate and statistical analysis was performed using One-Way ANOVA and Tukey's post hoc test for statistical significance $(\alpha=0.05)$ within GraphPad Prism v8.4.1.

\section{Author Contributions:}

RT wrote the manuscript, designed figures, generated strains, designed and executed stress granule assembly experiments, and performed heat shock survival assays. CC designed and executed colocalization experiments, generated strains, and performed quantification of Sts 5 puncta following heat stress. IN performed RNA-FISH analysis of Ssp1. PH provided technical support to RT and CC. FV designed experiments, edited the manuscript, and provided funding.

\section{Conflict of Interest Statement:}

The authors declare that this research was conducted in the absence of any commercial or financial relationships that could be construed as a potential conflict of interest.

\section{Funding:}

This work was funded by National Institutes of Health grant GM095867 (FV) and the Sylvester Comprehensive Cancer Center (FV). The funders had no role in the design or execution of the project or the decision to publish. 
bioRxiv preprint doi: https://doi.org/10.1101/2021.02.26.432566; this version posted February 27, 2021. The copyright holder for this preprint (which was not certified by peer review) is the author/funder. All rights reserved. No reuse allowed without permission.

Running Head: Orb6-Sts5 Regulates Stress Granules

\section{References:}

Adeyinka, A., Emberley, E., Niu, Y., Snell, L., Murphy, L.C., Sowter, H., Wykoff, C.C., Harris, A.L., and Watson, P.H. (2002). Analysis of gene expression in ductal carcinoma in situ of the breast. Clinical cancer research : an official journal of the American Association for Cancer Research 8, 3788-3795.

Aguzzi, A., and Altmeyer, M. (2016). Phase Separation: Linking Cellular Compartmentalization to Disease. Trends Cell Biol 26, 547-558.

Alberti, S., and Dormann, D. (2019). Liquid-Liquid Phase Separation in Disease. Annu Rev Genet 53, 171-194.

Anderson, P., and Kedersha, N. (2009). RNA granules: post-transcriptional and epigenetic modulators of gene expression. Nature reviews. Molecular cell biology 10, 430-436.

Anderson, P., Kedersha, N., and Ivanov, P. (2015). Stress granules, P-bodies and cancer. Biochim Biophys Acta 1849, 861-870.

Astuti, D., Morris, M.R., Cooper, W.N., Staals, R.H., Wake, N.C., Fews, G.A., Gill, H., Gentle, D., Shuib, S., Ricketts, C.J., Cole, T., van Essen, A.J., van Lingen, R.A., Neri, G., Opitz, J.M., Rump, P., StolteDijkstra, I., Muller, F., Pruijn, G.J., Latif, F., and Maher, E.R. (2012). Germline mutations in DIS3L2 cause the Perlman syndrome of overgrowth and Wilms tumor susceptibility. Nat Genet 44, 277-284.

Becker, L.A., and Gitler, A.D. (2015). It's all starting to come together. eLife 4.

Brangwynne, C.P. (2013). Phase transitions and size scaling of membrane-less organelles. The Journal of cell biology 203, 875-881.

Brangwynne, C.P., Eckmann, C.R., Courson, D.S., Rybarska, A., Hoege, C., Gharakhani, J., Julicher, F., and Hyman, A.A. (2009). Germline P granules are liquid droplets that localize by controlled

dissolution/condensation. Science (New York, N.Y.) 324, 1729-1732.

Brengues, M., and Parker, R. (2007). Accumulation of polyadenylated mRNA, Pab1p, elF4E, and elF4G with P-bodies in Saccharomyces cerevisiae. Mol Biol Cell 18, 2592-2602.

Buchan, J.R., Muhlrad, D., and Parker, R. (2008). P bodies promote stress granule assembly in Saccharomyces cerevisiae. The Journal of cell biology 183, 441-455.

Buchan, J.R., and Parker, R. (2009). Eukaryotic stress granules: the ins and outs of translation. Mol Cell 36, 932-941.

Chen, C., Rodriguez Pino, M., Haller, P.R., and Verde, F. (2019). Conserved NDR/LATS kinase controls RAS GTPase activity to regulate cell growth and chronological lifespan. Mol Biol Cell 30, 2598-2616.

Chiba, S., Ikeda, M., Katsunuma, K., Ohashi, K., and Mizuno, K. (2009). MST2- and Furry-mediated activation of NDR1 kinase is critical for precise alignment of mitotic chromosomes. Current biology : CB 19, 675-681.

Cornils, H., Kohler, R.S., Hergovich, A., and Hemmings, B.A. (2011). Downstream of human NDR kinases: impacting on c-myc and p21 protein stability to control cell cycle progression. Cell cycle (Georgetown, Tex.) 10, 1897-1904.

Cornils, H., Stegert, M.R., Hergovich, A., Hynx, D., Schmitz, D., Dirnhofer, S., and Hemmings, B.A. (2010). Ablation of the kinase NDR1 predisposes mice to the development of T cell lymphoma. Sci Signal 3, ra47.

Das, M., Drake, T., Wiley, D.J., Buchwald, P., Vavylonis, D., and Verde, F. (2012). Oscillatory dynamics of Cdc42 GTPase in the control of polarized growth. Science.

Das, M., Nunez, I., Rodriguez, M., Wiley, D.J., Rodriguez, J., Sarkeshik, A., Yates, J.R., 3rd, Buchwald, P., and Verde, F. (2015). Phosphorylation-dependent inhibition of Cdc42 GEF Gef1 by 14-3-3 protein Rad24 spatially regulates Cdc42 GTPase activity and oscillatory dynamics during cell morphogenesis. Mol Biol Cell 26, 3520-3534.

Das, M., Wiley, D.J., Chen, X., Shah, K., and Verde, F. (2009). The conserved NDR kinase Orb6 controls polarized cell growth by spatial regulation of the small GTPase Cdc42. Curr Biol 19, 1314-1319.

Elbaum-Garfinkle, S., Kim, Y., Szczepaniak, K., Chen, C.C., Eckmann, C.R., Myong, S., and Brangwynne, C.P. (2015). The disordered $P$ granule protein LAF-1 drives phase separation into droplets with tunable viscosity and dynamics. Proceedings of the National Academy of Sciences of the United States of America 112, 7189-7194.

Gilks, N., Kedersha, N., Ayodele, M., Shen, L., Stoecklin, G., Dember, L.M., and Anderson, P. (2004). Stress granule assembly is mediated by prion-like aggregation of TIA-1. Mol Biol Cell 15, 5383-5398. Guzikowski, A.R., Chen, Y.S., and Zid, B.M. (2019). Stress-induced mRNP granules: Form and function of processing bodies and stress granules. Wiley Interdiscip Rev RNA 10, e1524. 
bioRxiv preprint doi: https://doi.org/10.1101/2021.02.26.432566; this version posted February 27, 2021. The copyright holder for this preprint (which was not certified by peer review) is the author/funder. All rights reserved. No reuse allowed without permission.

Running Head: Orb6-Sts5 Regulates Stress Granules

Hanyu, Y., Imai, K.K., Kawasaki, Y., Nakamura, T., Nakaseko, Y., Nagao, K., Kokubu, A., Ebe, M., Fujisawa, A., Hayashi, T., Obuse, C., and Yanagida, M. (2009). Schizosaccharomyces pombe cell division cycle under limited glucose requires Ssp1 kinase, the putative CaMKK, and Sds23, a PP2Arelated phosphatase inhibitor. Genes Cells 14, 539-554.

Hauschild, A., Engel, G., Brenner, W., Glaser, R., Monig, H., Henze, E., and Christophers, E. (1999). $\mathrm{S} 100 \mathrm{~B}$ protein detection in serum is a significant prognostic factor in metastatic melanoma. Oncology 56, 338-344.

Heinrich, S., Geissen, E.M., Kamenz, J., Trautmann, S., Widmer, C., Drewe, P., Knop, M., Radde, N., Hasenauer, J., and Hauf, S. (2013). Determinants of robustness in spindle assembly checkpoint signalling. Nat Cell Biol 15, 1328-1339.

Hergovich, A., Kohler, R.S., Schmitz, D., Vichalkovski, A., Cornils, H., and Hemmings, B.A. (2009). The MST1 and hMOB1 tumor suppressors control human centrosome duplication by regulating NDR kinase phosphorylation. Current biology : CB 19, 1692-1702.

Hergovich, A., Lamla, S., Nigg, E.A., and Hemmings, B.A. (2007). Centrosome-associated NDR kinase regulates centrosome duplication. Mol Cell 25, 625-634.

Hergovich, A., Stegert, M.R., Schmitz, D., and Hemmings, B.A. (2006). NDR kinases regulate essential cell processes from yeast to humans. Nature reviews. Molecular cell biology 7, 253-264.

Higa, M., Kita, A., Hagihara, K., Kitai, Y., Doi, A., Nagasoko, R., Satoh, R., and Sugiura, R. (2015). Spatial control of calcineurin in response to heat shock in fission yeast. Genes Cells 20, 95-107.

Hofweber, M., and Dormann, D. (2019). Friend or foe-Post-translational modifications as regulators of phase separation and RNP granule dynamics. J Biol Chem 294, 7137-7150.

Hou, M.C., Wiley, D.J., Verde, F., and McCollum, D. (2003). Mob2p interacts with the protein kinase Orb6p to promote coordination of cell polarity with cell cycle progression. J Cell Sci 116, 125-135.

Hyman, A.A., Weber, C.A., and Julicher, F. (2014). Liquid-liquid phase separation in biology. Annual review of cell and developmental biology 30, 39-58.

Ingelfinger, D., Arndt-Jovin, D.J., Luhrmann, R., and Achsel, T. (2002). The human LSm1-7 proteins colocalize with the mRNA-degrading enzymes Dcp1/2 and Xrnl in distinct cytoplasmic foci. RNA (New York, N.Y.) 8, 1489-1501.

Jain, S., Wheeler, J.R., Walters, R.W., Agrawal, A., Barsic, A., and Parker, R. (2016). ATPase-Modulated Stress Granules Contain a Diverse Proteome and Substructure. Cell 164, 487-498.

Jansen, J.M., Wanless, A.G., Seidel, C.W., and Weiss, E.L. (2009). Cbk1 regulation of the RNA-binding protein Ssd1 integrates cell fate with translational control. Curr Biol 19, 2114-2120.

Kanda, Y., Satoh, R., Takasaki, T., Tomimoto, N., Tsuchiya, K., Tsai, C.A., Tanaka, T., Kyomoto, S., Hamada, K., Fujiwara, T., and Sugiura, R. (2021). Sequestration of the PKC ortholog Pck2 in stress granules as a feedback mechanism of MAPK signaling in fission yeast. J Cell Sci 134.

Kato, M., Han, T.W., Xie, S., Shi, K., Du, X., Wu, L.C., Mirzaei, H., Goldsmith, E.J., Longgood, J., Pei, J., Grishin, N.V., Frantz, D.E., Schneider, J.W., Chen, S., Li, L., Sawaya, M.R., Eisenberg, D., Tycko, R., and McKnight, S.L. (2012). Cell-free formation of RNA granules: low complexity sequence domains form dynamic fibers within hydrogels. Cell 149, 753-767.

Kedersha, N., Stoecklin, G., Ayodele, M., Yacono, P., Lykke-Andersen, J., Fritzler, M.J., Scheuner, D., Kaufman, R.J., Golan, D.E., and Anderson, P. (2005). Stress granules and processing bodies are dynamically linked sites of mRNP remodeling. J Cell Biol 169, 871-884.

Klosinska, M.M., Crutchfield, C.A., Bradley, P.H., Rabinowitz, J.D., and Broach, J.R. (2011). Yeast cells can access distinct quiescent states. Genes Dev 25, 336-349.

Kroschwald, S., and Alberti, S. (2017). Gel or Die: Phase Separation as a Survival Strategy. Cell 168, 947-948.

Kroschwald, S., Maharana, S., Mateju, D., Malinovska, L., Nuske, E., Poser, I., Richter, D., and Alberti, S. (2015). Promiscuous interactions and protein disaggregases determine the material state of stressinducible RNP granules. eLife 4, e06807.

Kurischko, C., Kim, H.K., Kuravi, V.K., Pratzka, J., and Luca, F.C. (2011). The yeast Cbk1 kinase regulates mRNA localization via the mRNA-binding protein Ssd1. J Cell Biol 192, 583-598.

Lee, C.F., Brangwynne, C.P., Gharakhani, J., Hyman, A.A., and Julicher, F. (2013). Spatial organization of the cell cytoplasm by position-dependent phase separation. Physical review letters 111, 088101.

Lin, Y., Protter, D.S., Rosen, M.K., and Parker, R. (2015). Formation and Maturation of Phase-Separated Liquid Droplets by RNA-Binding Proteins. Mol Cell 60, 208-219. 
bioRxiv preprint doi: https://doi.org/10.1101/2021.02.26.432566; this version posted February 27, 2021. The copyright holder for this preprint (which was not certified by peer review) is the author/funder. All rights reserved. No reuse allowed without permission.

Running Head: Orb6-Sts5 Regulates Stress Granules

Lv, H., Zhu, Y., Qiu, Y., Niu, L., Teng, M., and Li, X. (2015). Structural analysis of Dis3l2, an exosomeindependent exonuclease from Schizosaccharomyces pombe. Acta Crystallogr D Biol Crystallogr 71, 1284-1294.

Magliozzi, J.O., Sears, J., Cressey, L., Brady, M., Opalko, H.E., Kettenbach, A.N., and Moseley, J.B. (2020). Fission yeast Pak1 phosphorylates anillin-like Mid1 for spatial control of cytokinesis. J Cell Biol 219.

Mahboubi, H., and Stochaj, U. (2017). Cytoplasmic stress granules: Dynamic modulators of cell signaling and disease. Biochim Biophys Acta Mol Basis Dis 1863, 884-895.

Malecki, M., Viegas, S.C., Carneiro, T., Golik, P., Dressaire, C., Ferreira, M.G., and Arraiano, C.M. (2013). The exoribonuclease Dis3L2 defines a novel eukaryotic RNA degradation pathway. EMBO J 32, 1842-1854.

Matsusaka, T., Hirata, D., Yanagida, M., and Toda, T. (1995). A novel protein kinase gene ssp1+ is required for alteration of growth polarity and actin localization in fission yeast. EMBO J 14, 3325-3338. Miller, C.L. (2011). Stress Granules and Virus Replication. Future Virol 6, 1329-1338.

Millward, T.A., Heizmann, C.W., Schafer, B.W., and Hemmings, B.A. (1998). Calcium regulation of Ndr protein kinase mediated by $S 100$ calcium-binding proteins. The EMBO journal 17, 5913-5922.

Mitchison, J.M., and Nurse, P. (1985). Growth in cell length in the fission yeast Schizosaccharomyces pombe. J Cell Sci 75, 357-376.

Munder, M.C., Midtvedt, D., Franzmann, T., Nuske, E., Otto, O., Herbig, M., Ulbricht, E., Muller, P., Taubenberger, A., Maharana, S., Malinovska, L., Richter, D., Guck, J., Zaburdaev, V., and Alberti, S. (2016). A pH-driven transition of the cytoplasm from a fluid- to a solid-like state promotes entry into dormancy. Elife 5.

Napoletano, F., Occhi, S., Calamita, P., Volpi, V., Blanc, E., Charroux, B., Royet, J., and Fanto, M. (2011). Polyglutamine Atrophin provokes neurodegeneration in Drosophila by repressing fat. The EMBO journal 30, 945-958.

Nilsson, D., and Sunnerhagen, P. (2011). Cellular stress induces cytoplasmic RNA granules in fission yeast. RNA (New York, N.Y.) 17, 120-133.

Nunez, I., Rodriguez Pino, M., Wiley, D.J., Das, M.E., Chen, C., Goshima, T., Kume, K., Hirata, D., Toda, T., and Verde, F. (2016). Spatial control of translation repression and polarized growth by conserved NDR kinase Orb6 and RNA-binding protein Sts5. Elife 5.

Onomoto, K., Yoneyama, M., Fung, G., Kato, H., and Fujita, T. (2014). Antiviral innate immunity and stress granule responses. Trends Immunol 35, 420-428.

Owen, I., and Shewmaker, F. (2019). The Role of Post-Translational Modifications in the Phase

Transitions of Intrinsically Disordered Proteins. Int J Mol Sci 20.

Patel, A., Lee, H.O., Jawerth, L., Maharana, S., Jahnel, M., Hein, M.Y., Stoynov, S., Mahamid, J., Saha, S., Franzmann, T.M., Pozniakovski, A., Poser, I., Maghelli, N., Royer, L.A., Weigert, M., Myers, E.W., Grill, S., Drechsel, D., Hyman, A.A., and Alberti, S. (2015). A Liquid-to-Solid Phase Transition of the ALS Protein FUS Accelerated by Disease Mutation. Cell 162, 1066-1077.

Poblete-Duran, N., Prades-Perez, Y., Vera-Otarola, J., Soto-Rifo, R., and Valiente-Echeverria, F. (2016). Who Regulates Whom? An Overview of RNA Granules and Viral Infections. Viruses 8.

Ramaswami, M., Taylor, J.P., and Parker, R. (2013). Altered ribostasis: RNA-protein granules in degenerative disorders. Cell 154, 727-736.

Riback, J.A., Katanski, C.D., Kear-Scott, J.L., Pilipenko, E.V., Rojek, A.E., Sosnick, T.R., and Drummond, D.A. (2017). Stress-Triggered Phase Separation Is an Adaptive, Evolutionarily Tuned Response. Cell 168, 1028-1040 e1019.

Robinson, S.R., Oliver, A.W., Chevassut, T.J., and Newbury, S.F. (2015). The 3' to 5' Exoribonuclease DIS3: From Structure and Mechanisms to Biological Functions and Role in Human Disease. Biomolecules 5, 1515-1539.

Ross, D.T., Scherf, U., Eisen, M.B., Perou, C.M., Rees, C., Spellman, P., lyer, V., Jeffrey, S.S., Van de Rijn, M., Waltham, M., Pergamenschikov, A., Lee, J.C., Lashkari, D., Shalon, D., Myers, T.G., Weinstein, J.N., Botstein, D., and Brown, P.O. (2000). Systematic variation in gene expression patterns in human cancer cell lines. Nature genetics 24, 227-235.

Sakuno, T., Araki, Y., Ohya, Y., Kofuji, S., Takahashi, S., Hoshino, S., and Katada, T. (2004). Decapping reaction of mRNA requires Dcp1 in fission yeast: its characterization in different species from yeast to human. Journal of biochemistry 136, 805-812. 
bioRxiv preprint doi: https://doi.org/10.1101/2021.02.26.432566; this version posted February 27, 2021. The copyright holder for this preprint (which was not certified by peer review) is the author/funder. All rights reserved. No reuse allowed without permission.

Running Head: Orb6-Sts5 Regulates Stress Granules

Satoh, R., Tanaka, A., Kita, A., Morita, T., Matsumura, Y., Umeda, N., Takada, M., Hayashi, S., Tani, T., Shinmyozu, K., and Sugiura, R. (2012). Role of the RNA-binding protein Nrd1 in stress granule formation and its implication in the stress response in fission yeast. PLoS One 7, e29683.

Schneider, C.A., Rasband, W.S., and Eliceiri, K.W. (2012). NIH Image to ImageJ: 25 years of image analysis. Nat Methods 9, 671-675.

Stoecklin, G., and Kedersha, N. (2013). Relationship of GW/P-bodies with stress granules. Adv Exp Med Biol 768, 197-211.

Tay, Y.D., Leda, M., Spanos, C., Rappsilber, J., Goryachev, A.B., and Sawin, K.E. (2019). Fission Yeast NDR/LATS Kinase Orb6 Regulates Exocytosis via Phosphorylation of the Exocyst Complex. Cell Rep 26, 1654-1667 e1657.

Toda, T., Niwa, H., Nemoto, T., Dhut, S., Eddison, M., Matsusaka, T., Yanagida, M., and Hirata, D. (1996). The fission yeast sts5+ gene is required for maintenance of growth polarity and functionally interacts with protein kinase $C$ and an osmosensing MAP-kinase pathway. J Cell Sci 109 ( Pt 9), 23312342.

Vaggi, F., Dodgson, J., Bajpai, A., Chessel, A., Jordan, F., Sato, M., Carazo-Salas, R.E., and CsikaszNagy, A. (2012). Linkers of cell polarity and cell cycle regulation in the fission yeast protein interaction network. PLoS Comput Biol 8, e1002732.

van Dijk, E., Cougot, N., Meyer, S., Babajko, S., Wahle, E., and Seraphin, B. (2002). Human Dcp2: a catalytically active mRNA decapping enzyme located in specific cytoplasmic structures. The EMBO journal 21, 6915-6924.

Verde, F., Mata, J., and Nurse, P. (1995). Fission yeast cell morphogenesis: identification of new genes and analysis of their role during the cell cycle. J Cell Biol 131, 1529-1538.

Verde, F., Wiley, D.J., and Nurse, P. (1998). Fission yeast orb6, a ser/thr protein kinase related to mammalian rho kinase and myotonic dystrophy kinase, is required for maintenance of cell polarity and coordinates cell morphogenesis with the cell cycle. Proceedings of the National Academy of Sciences of the United States of America 95, 7526-7531.

Vichalkovski, A., Gresko, E., Cornils, H., Hergovich, A., Schmitz, D., and Hemmings, B.A. (2008). NDR kinase is activated by RASSF1A/MST1 in response to Fas receptor stimulation and promotes apoptosis. Current biology : CB 18, 1889-1895.

Wang, Z., Jiao, X., Carr-Schmid, A., and Kiledjian, M. (2002). The hDcp2 protein is a mammalian mRNA decapping enzyme. Proceedings of the National Academy of Sciences of the United States of America 99, 12663-12668.

Wen, W.L., Stevenson, A.L., Wang, C.Y., Chen, H.J., Kearsey, S.E., Norbury, C.J., Watt, S., Bahler, J., and Wang, S.W. (2010). Vgl1, a multi-KH domain protein, is a novel component of the fission yeast stress granules required for cell survival under thermal stress. Nucleic Acids Res 38, 6555-6566.

Wheeler, J.R., Matheny, T., Jain, S., Abrisch, R., and Parker, R. (2016). Distinct stages in stress granule assembly and disassembly. Elife 5 .

Yang, R., Kong, E., Jin, J., Hergovich, A., and Puschel, A.W. (2014). Rassf5 and Ndr kinases regulate neuronal polarity through Par3 phosphorylation in a novel pathway. Journal of cell science 127, 34633476.

Zhang, L., Tang, F., Terracciano, L., Hynx, D., Kohler, R., Bichet, S., Hess, D., Cron, P., Hemmings, B.A., Hergovich, A., and Schmitz-Rohmer, D. (2015). NDR functions as a physiological YAP1 kinase in the intestinal epithelium. Current biology : CB 25, 296-305. 
Running Head: Orb6-Sts5 Regulates Stress Granules

Figure 1. Sts5-3xGFP co-localized with P-bodies after different types of stress. sts5-3xGFP dcp1-mCherry cells were cultured in YES medium, centrifuged, and resuspended in YES medium (a-c) as an untreated control. To induce stress, cells were resuspended in YES containing either $10 \mathrm{mM} \mathrm{H}_{2} \mathrm{O}_{2}$ for 1 hour (d-f), $1 \mathrm{M}$ $\mathrm{NaCl}$ for 30 minutes $(\mathrm{g}-\mathrm{i})$, or heat shocked at $42^{\circ} \mathrm{C}$ for 20 minutes $(\mathrm{j}-\mathrm{l})$. In all three conditions Sts5-3xGFP forms cytoplasmic puncta which partially co-localized with the P-body marker Dcp1-mCherry, whereas the untreated controls display little to no formation of P-Bodies or puncta. Images are deconvolved projections from Z-stacks separated by a step size of $0.3 \mu \mathrm{M}($ Bar $=5 \mu \mathrm{M})$.

Figure 2. Sts5-3xGFP co-localized with stress granules and Sts5-ssp1 associated mRNA following stress. (A) sts5-3xGFP pabp1-DsRed cells were cultured in medium with glucose $(A ; a-c)$ or without glucose $(A ; d-$ f) for 30 minutes. Upon glucose deprivation, Sts5-3xGFP coalesced into cytoplasmic puncta which partially co-localized with the stress granule marker Pabp1-DsRed. (B) sts5-3xGFP pabp1-DsRed cells were cultured in YES medium as the untreated control condition (B; a-c). To induce stress, cells were resuspended in YES containing either $10 \mathrm{mM} \mathrm{H}_{2} \mathrm{O}_{2}$ for 1 hour (B; d-f), $1 \mathrm{M} \mathrm{NaCl}$ for 30 minutes (B; g-i), or heat shocked at $42^{\circ} \mathrm{C}$ for 20 minutes $(\mathrm{B} ; \mathrm{j}-\mathrm{I})$. In all three conditions, Sts5-3xGFP formed cytoplasmic puncta which partially co-localized with the stress granule marker Pabp1-DsRed. (C) RNA FISH visualization of ssp1 mRNA in fixed cells cultured for 20 minutes in minimal medium containing $0 \%$ glucose. Hybridization of RNA was performed with 20-mer DNA oligonucleotides (Stellaris) labeled with Quasar 705 fluorochromes. ssp1 mRNA co-localized with Sts5-3xGFP and the stress granule marker Pabp1-DsRed (arrows). Images are deconvolved projections from Z-stacks separated by a step size of $0.3 \mu \mathrm{M}$ (Bar $=5 \mu \mathrm{M})$.

Figure 3. Orb6 and Sts5 regulate stress granule formation. (A) pabp1-DsRed and sts5 $\Delta$ pabp1-DsRed cells were cultured in EMM medium with $(a, c)$ or without $(b, d)$ glucose for 20 minutes. In untreated controls, the stress granule marker Pabp1-DsRed remained diffuse throughout the cytoplasm. Following glucose deprivation, sts $5 \Delta$ cells formed less stress granules than the control (b, d). (B) The number of stress granules were quantified for three separate experiments ( $N=90$ cells/strain/condition total), and there was a statistically significant decrease in stress granule formation for the sts $5 \Delta$ mutant as compared to the control ( ${ }^{* * *} p<0.001$; unpaired t-test). (C) Inhibition of Orb6 primes cells for the formation of stress granules. 
Running Head: Orb6-Sts5 Regulates Stress Granules

orb6-as2 pabp1-DsRed cells were cultured in minimal medium containing adenine, and 15 minutes prior to heat shock 1-NA-PP1 inhibitor was added, or DMSO for controls. In cells maintained at $25^{\circ} \mathrm{C}$, Pabp1-DsRed remained diffuse within the cytoplasm $(a, c)$. However, in cells that were heat shocked for 20 minutes at $42^{\circ} \mathrm{C}$ (15 minutes post addition of 1-NA-PP1), there was an increase in stress granule formation compared to the DMSO control (b, d). (D) This experiment was performed three times and the increase in stress granule formation was statistically significant ( $\mathrm{N}=90$ cells/strain/condition total; ${ }^{* * *} \mathrm{p}<0.001$, unpaired t-test). Representative images are deconvolved projections from Z-stacks separated by a step size of $0.3 \mu \mathrm{M}$ (Bar $=5 \mu \mathrm{M})$.

Figure 4. Orb6 and Sts5 modulate survival following heat stress. (A) Wild-type, sts5 sts5S86A-HA cells were exposed to a $48^{\circ} \mathrm{C}$ temperature shift for 20 minutes, while untreated controls were incubated at $25^{\circ} \mathrm{C}$. Following heat stress, sts $5 \Delta$ cells exhibit decreased survival, whereas the sts $5 S 86 \mathrm{~A}-\mathrm{HA}$ mutant exhibited increased survival ${ }^{* * *} p<0.001$; One-Way ANOVA with Tukey's test). (B) The experiment in A was repeated, but cells were instead incubated for 6 hours at either $25^{\circ} \mathrm{C}$ or $36.5^{\circ} \mathrm{C}$. Again, sts $5 \Delta$ cells displayed decreased survival compared to wild type, whereas sts5S86A-HA had increased survival compared to the sts5-HA control ${ }^{* * *} \mathrm{p}<0.001$; One-Way ANOVA with Tukey's test). (C) In the sts5S86A$3 x$ YFP mutant, the number of Sts5 granules were increased at temperatures in which the sts5-3xYFP control did not form granules. (D) Quantification from results obtained in C. There is a statistically significant increase in average puncta per cell for the sts5S86A-3xYFP strain as compared to the control for cells incubated between $25^{\circ} \mathrm{C}$ and $35.5^{\circ} \mathrm{C}\left(\mathrm{N}=60\right.$ cells/strain, ${ }^{* * *} \mathrm{p}<0.001,{ }^{* *} \mathrm{p}<0.01,{ }^{*} \mathrm{p}<0.05$; One-Way ANOVA with Tukey's test). (E) Wild-type and orb6-as2 strains were cultured in the presence $(+T)$ or absence of thiamine, heat shocked, and plated for CFUs/mL. Inhibition of Orb6 results in a 17-fold increase in survival as compared to the untreated control ( ${ }^{* *} p<0.001$; One-Way ANOVA with Tukey's test).

Figure 5. Model for Sts5 activation and response to stress. (A) Under optimal growth conditions, the RNA binding protein Sts5 is phosphorylated by the NDR kinase Orb6. This results in binding of Sts5 to the 14-33 protein Rad24 and promotes translation of Sts 5 bound mRNA. Under these conditions, there is little to no formation of RNP granules. (B) Following exposure to heat stress, oxidative stress, osmotic stress, or 
Running Head: Orb6-Sts5 Regulates Stress Granules

nutrient starvation, Sts5 coalesces into cytoplasmic puncta which partially co-localize with P-Bodies and stress granules. (C) Loss of Sts5 decreases the formation of stress granules, and cells are less tolerant to heat stress. (D) Inhibition of Orb6 drastically increases resilience to heat stress and promotes the formation of stress granules after heat stress. The sts 5 S $86 \mathrm{~A}$ mutant exhibits increased Sts 5 coalescence and is more resilient to heat stress.

Supplemental Figure 1. Representative image of the orb6-as2 heat shock assay (10-2 dilution) from the heat shocked sample set. Inhibition of Orb6 drastically increases survival (bottom right) after exposure to a $48^{\circ} \mathrm{C}$ heat shock for 15 minutes, as compared to untreated or wild-type controls. 

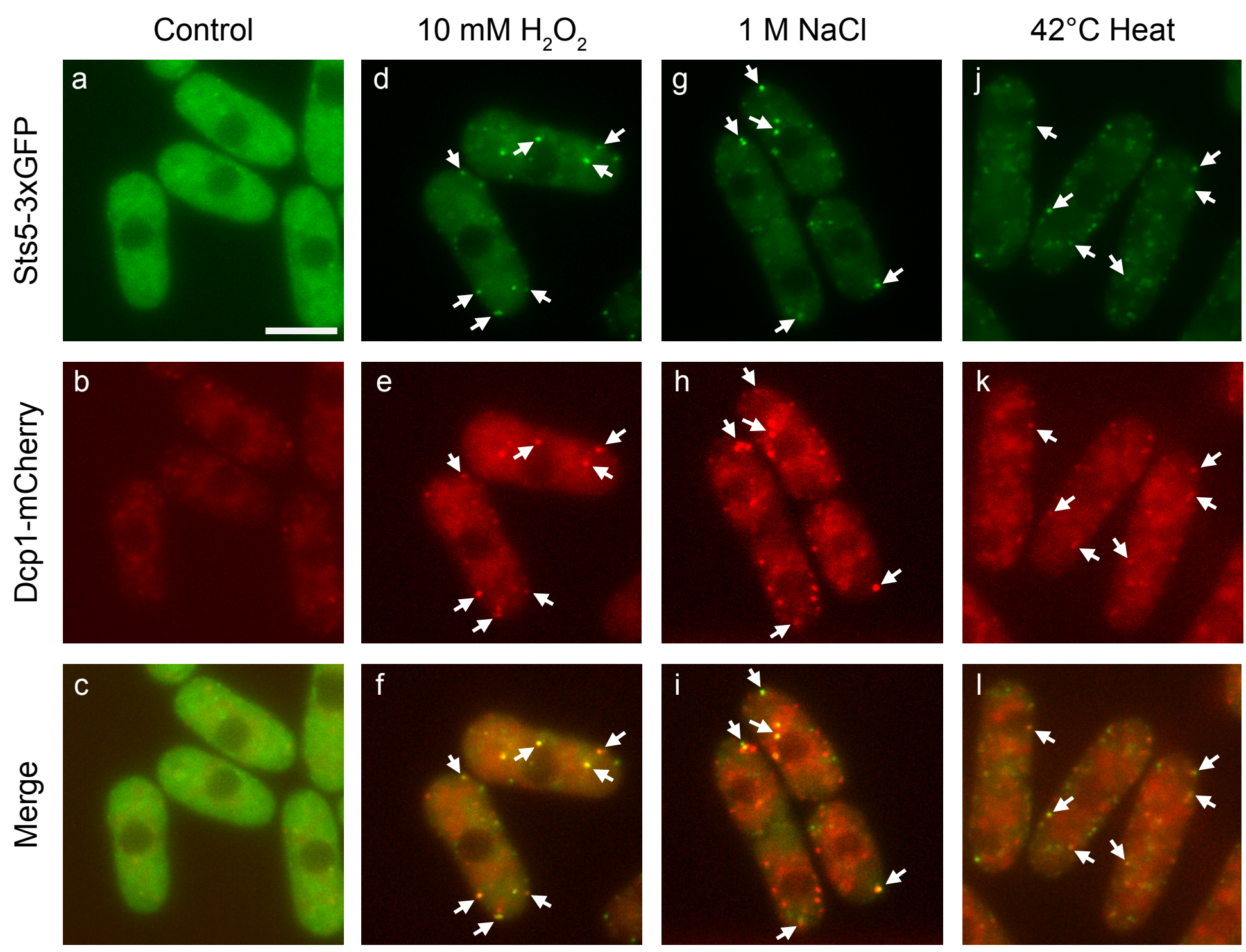

Figure 1. Sts5-3xGFP co-localized with P-bodies after different types of stress. sts5-3xGFP dcp1-mCherry cells were cultured in YES medium, centrifuged, and resuspended in YES medium (a-c) as an untreated control. To induce stress, cells were resuspended in YES containing either 10 $\mathrm{mM} \mathrm{H}_{2} \mathrm{O}_{2}$ for 1 hour (d-f), $1 \mathrm{M} \mathrm{NaCl}$ for 30 minutes $(\mathrm{g}-\mathrm{i})$, or heat shocked at $42^{\circ} \mathrm{C}$ for 20 minutes $(\mathrm{j}-\mathrm{I})$. In all three conditions Sts5-3xGFP formed cytoplasmic puncta which partially co-localized with the P-body marker Dcp1-mCherry, whereas the untreated controls displayed little to no formation of P-Bodies or puncta. Images are deconvolved projections from Z-stacks separated by a step size of $0.3 \mu \mathrm{M}(\mathrm{Bar}=5 \mu \mathrm{M})$. 

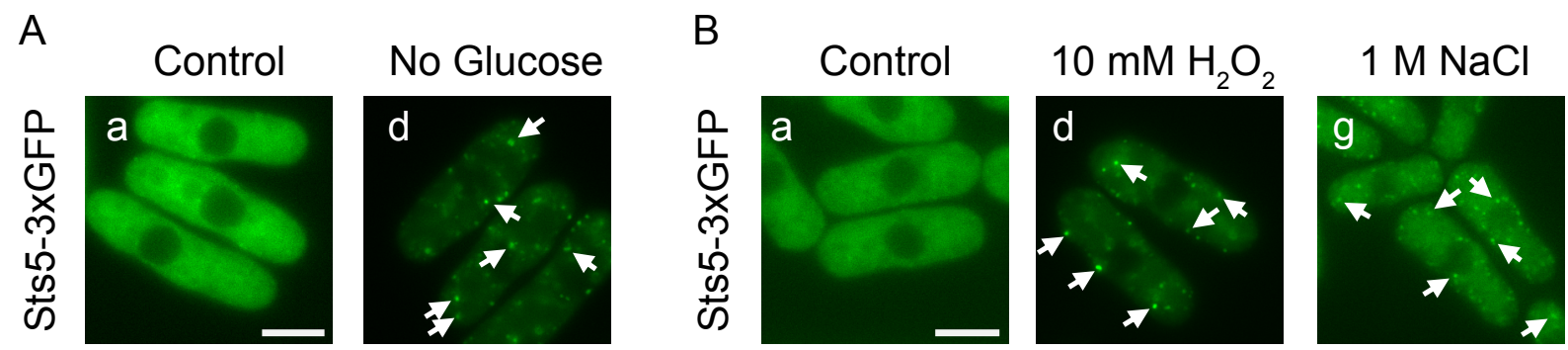

$42^{\circ} \mathrm{C}$ Heat
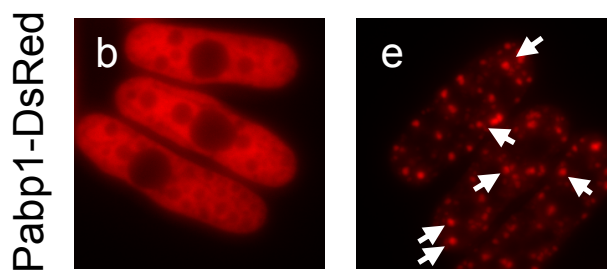

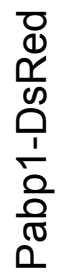
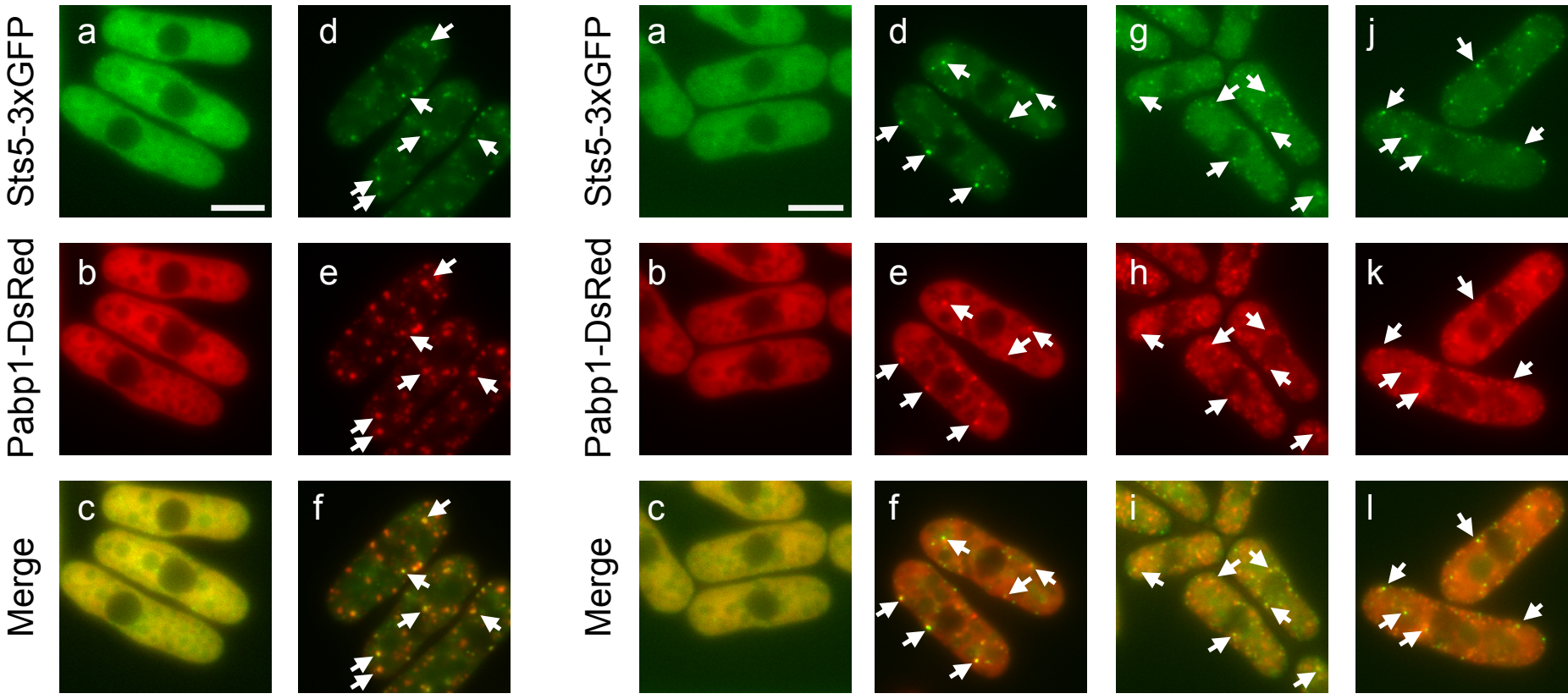

C

ssp 1 mRNA

Sts5-3xGFP

Pabp1-DsRed
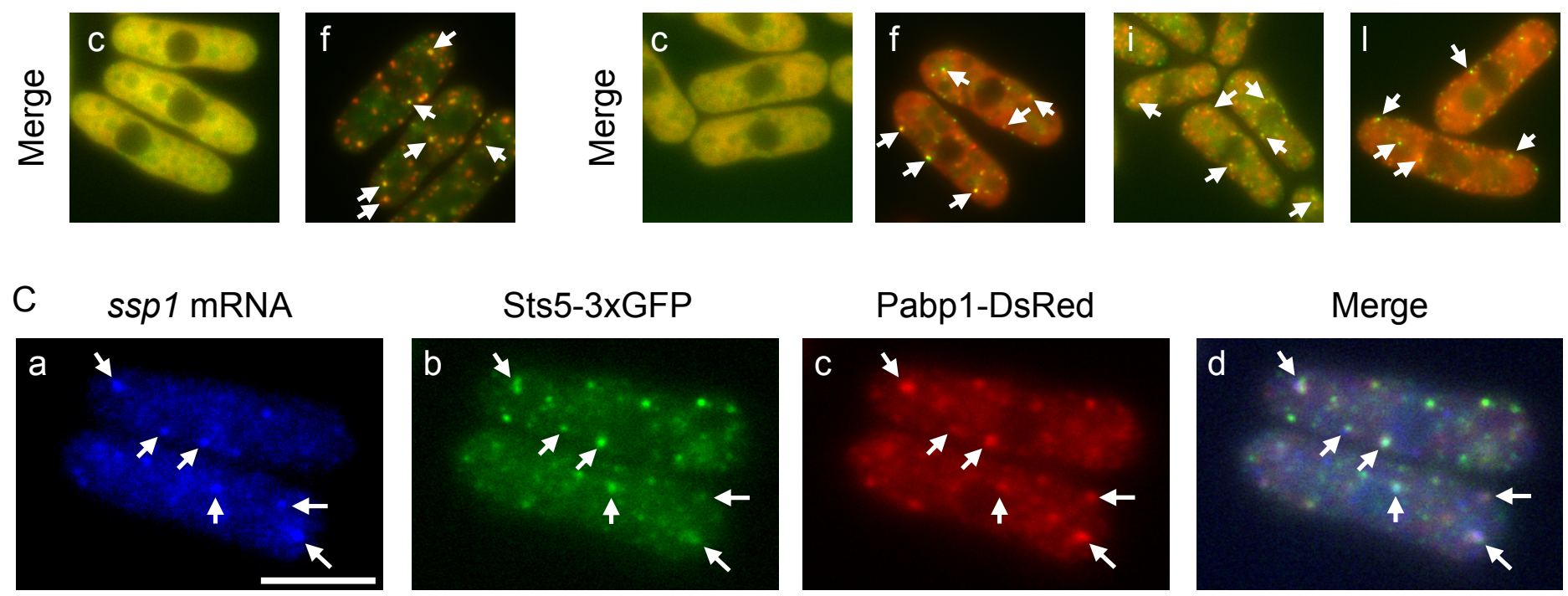

Figure 2. Sts5-3xGFP co-localized with stress granules and Sts5-ssp1 associated mRNA following stress. (A) sts5-3xGFP pabp1-DsRed cells were cultured in EMM medium with glucose $(A$; a-c) or without glucose (A; d-f) for 30 minutes. Upon glucose deprivation, Sts5-3xGFP coalesced into cytoplasmic puncta which partially co-localized with the stress granule marker Pabp1-DsRed. (B) sts5-3xGFP pabp1-DsRed cells were cultured in YES medium as the untreated control condition (B; a-c). To induce stress, cells were resuspended in YES containing either $10 \mathrm{mM} \mathrm{H}_{2} \mathrm{O}_{2}$ for 1 hour ( $B$; d-f), $1 \mathrm{M} \mathrm{NaCl}$ for 30 minutes (B; g-i), or heat shocked at $42^{\circ} \mathrm{C}$ for 20 minutes $(\mathrm{B}$; j-I). In all three conditions, Sts5-3xGFP formed cytoplasmic puncta which partially co-localized with the stress granule marker Pabp1-DsRed. (C) RNA FISH visualization of ssp1 mRNA in fixed cells cultured for 20 minutes in minimal medium containing $0 \%$ glucose. Hybridization of RNA was performed with 20-mer DNA oligonucleotides (Stellaris) labeled with Quasar 705 fluorochromes. ssp1 mRNA co-localized with Sts5-3xGFP and the stress granule marker Pabp1-DsRed (arrows). Images are deconvolved projections from Z-stacks separated by a step size of $0.3 \mu \mathrm{M}($ Bar $=5 \mu \mathrm{M})$. 


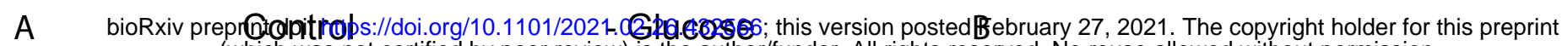
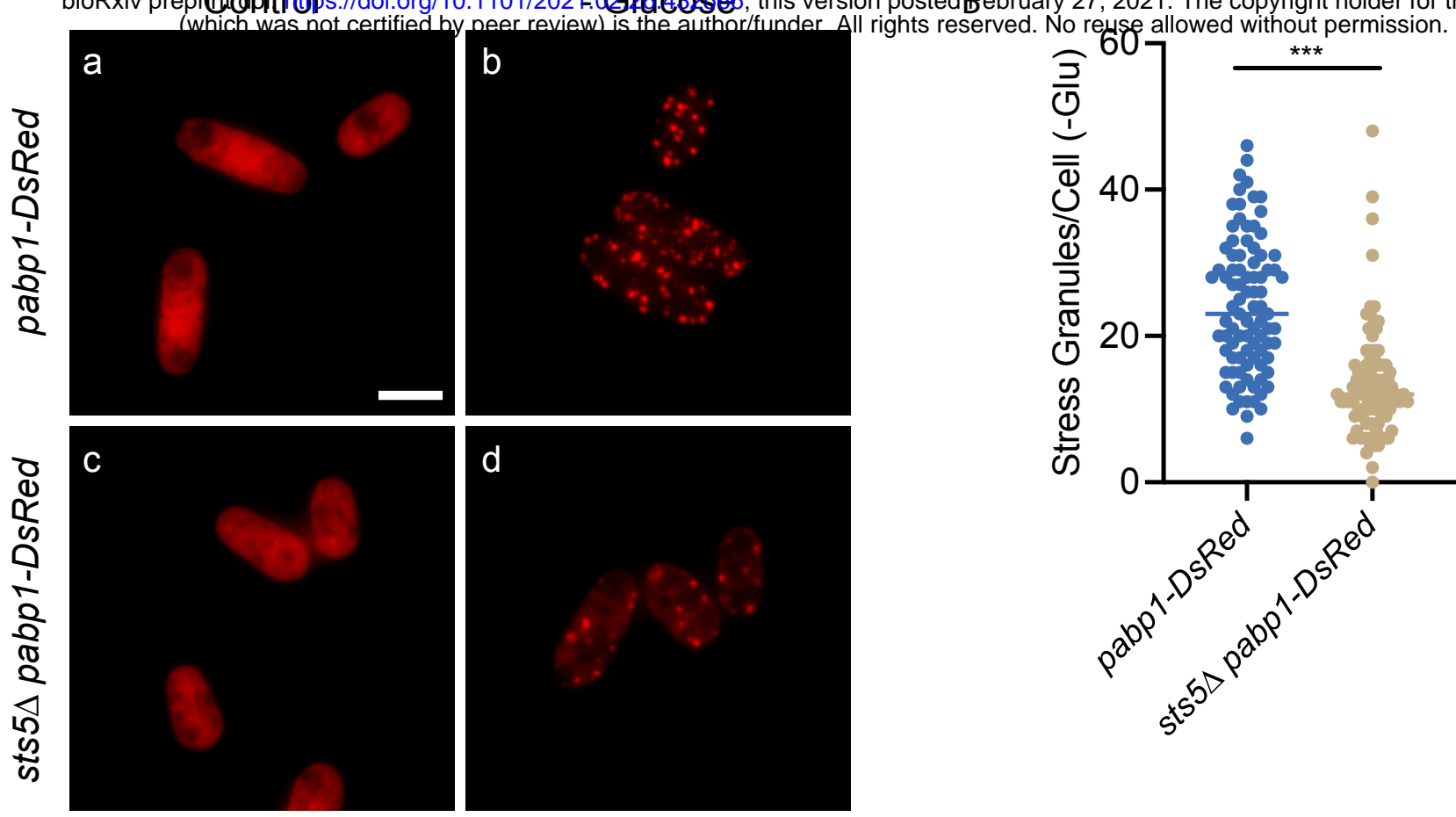

C

orb6-as2 pabp1-DsRed
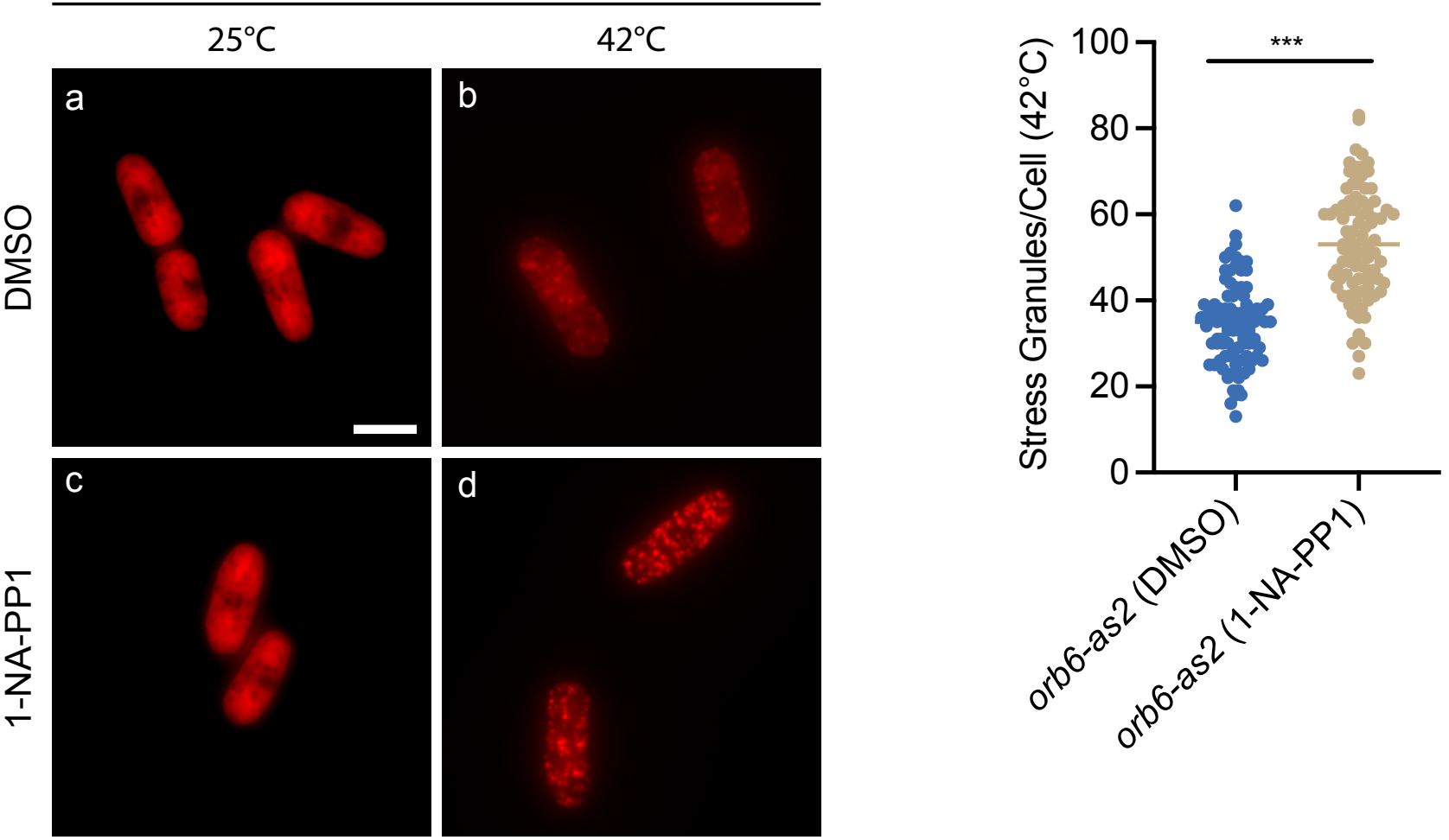

Figure 3. Orb6 and Sts 5 regulate stress granule formation. (A) pabp1-DsRed and sts5 pabp1-DsRed cells were cultured in EMM medium with $(a, c)$ or without $(b, d)$ glucose for 20 minutes. In untreated controls, the stress granule marker Pabp1-DsRed remained diffuse throughout the cytoplasm. Following glucose deprivation, sts5 $\Delta$ cells formed less stress granules than the control $(b, d)$. (B) The number of stress granules were quantified for three separate experiments $(\mathrm{N}=90 \mathrm{cell} / \mathrm{s} / \mathrm{strain} / \mathrm{condition}$ total), and there was a statistically significant decrease in stress granule formation for the sts $5 \Delta$ mutant as compared to the control ${ }^{* * *} p<0.001$; unpaired t-test). (C) Inhibition of Orb6 primes cells for the formation of stress granules. orb6-as2 pabp1-DsRed cells were cultured in minimal medium containing adenine, and 15 minutes prior to heat shock 1-NA-PP1 inhibitor was added, or DMSO for controls. In cells maintained at $25^{\circ} \mathrm{C}$, Pabp1-DsRed remained diffuse within the cytoplasm (a, c). However, in cells that were heat shocked for 20 minutes at $42^{\circ} \mathrm{C}(15$ minutes post addition of 1-NA-PP1), there was an increase in stress granule formation compared to the DMSO control (b, d). (D) This experiment was performed three times and the increase in stress granule formation was statistically significant $\left(\mathrm{N}=90\right.$ cells/strain/condition total; ${ }^{* * *} \mathrm{p}<0.001$, unpaired t-test). Representative images are deconvolved projections from Z-stacks separated by a step size of 0.3 $\mu \mathrm{M}(\mathrm{Bar}=5 \mu \mathrm{M})$ 
biARxiv preprint doi: https://doi.org/10.1101/2021.02.26.432566; this versiß̧ posted February 27, 2021. The copyright holder for this preprint

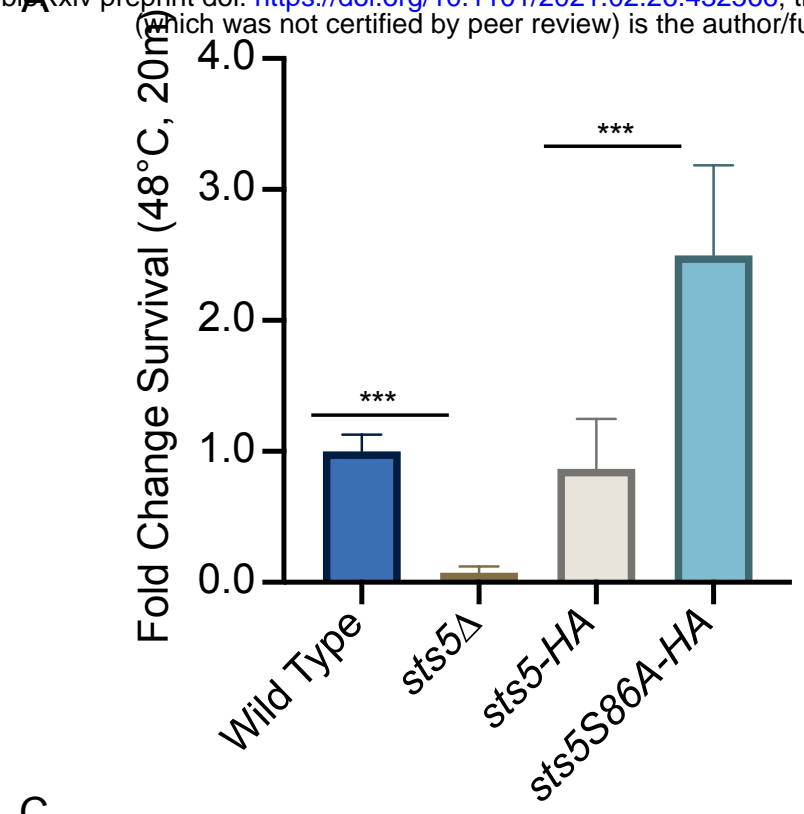

C
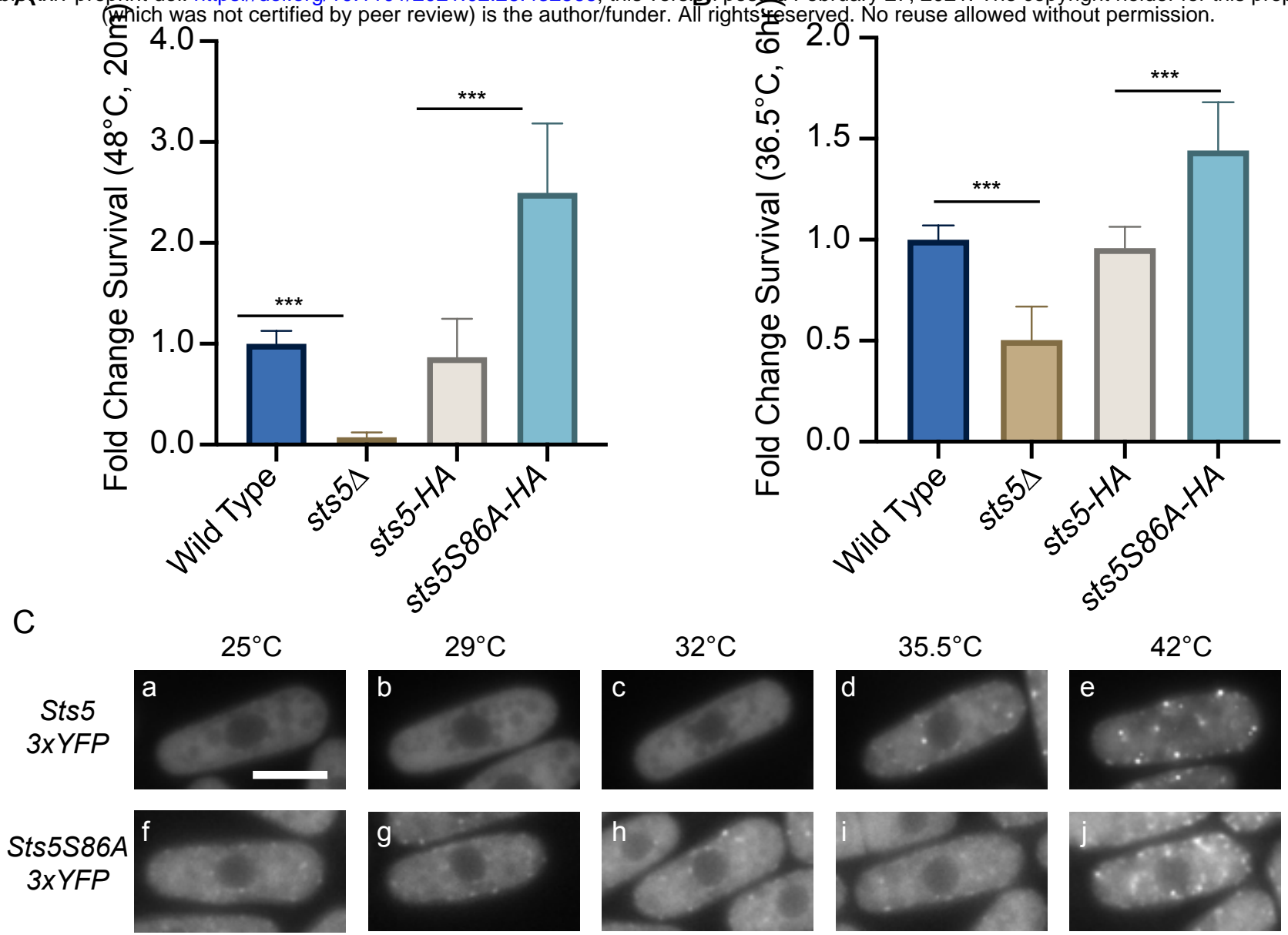

D
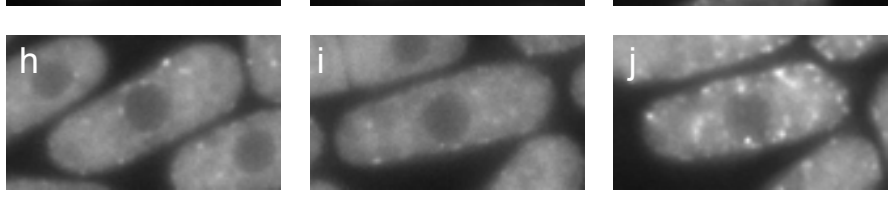

E
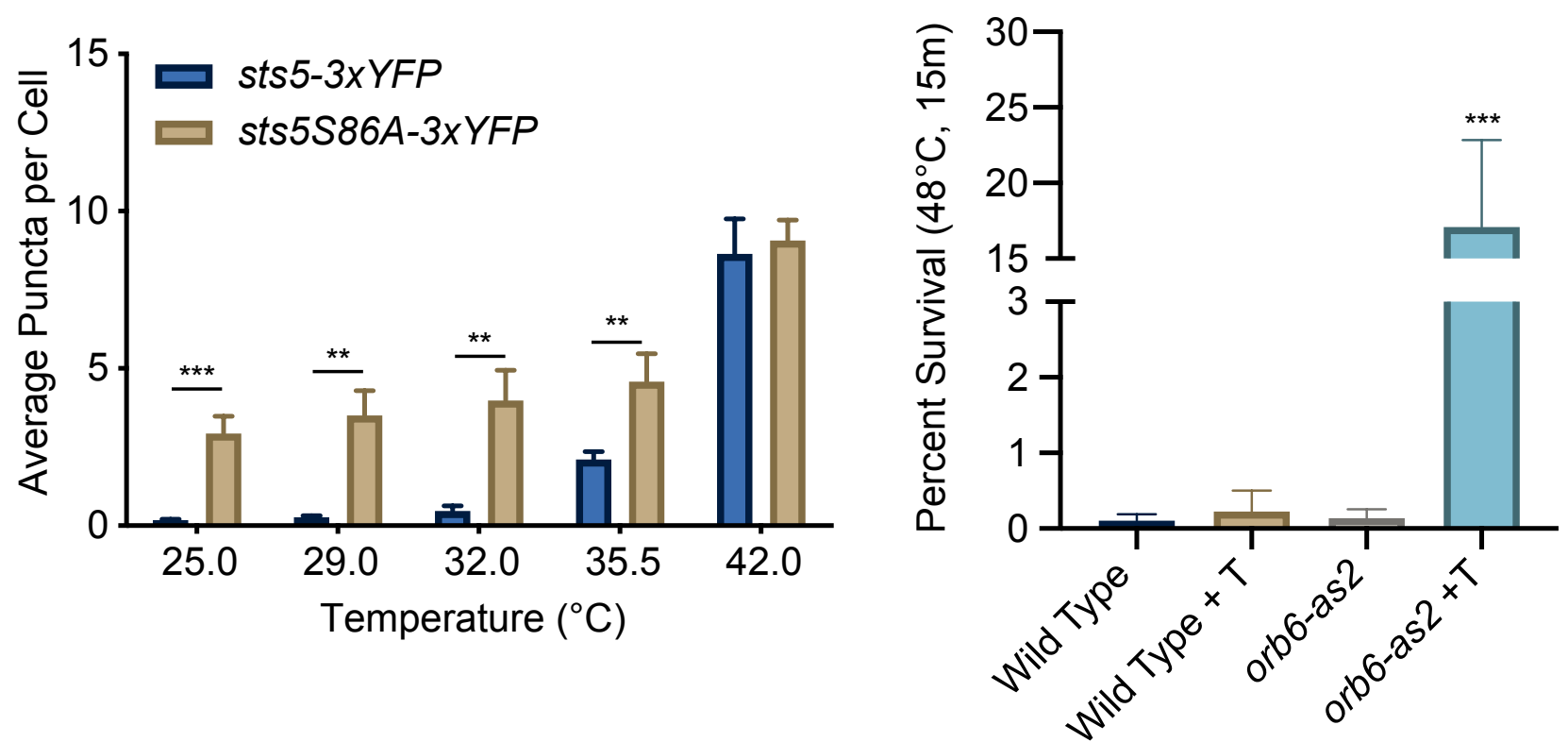

Figure 4. Orb6 and Sts5 modulate survival following heat stress. (A) Wild-type, sts5 cells were exposed to a $48^{\circ} \mathrm{C}$ temperature shift for 20 minutes, while untreated controls were incubated at $25^{\circ} \mathrm{C}$. Following heat stress, sts $5 \Delta$ cells exhibit decreased survival, whereas the sts $5 S 86 A-H A$ mutant exhibited increased survival ( ${ }^{* * *} p<0.001$; One-Way ANOVA with Tukey's test). (B) The experiment in A was repeated, but cells were instead incubated for 6 hours at either $25^{\circ} \mathrm{C}$ or $36.5^{\circ} \mathrm{C}$. Again, sts $5 \Delta$ cells displayed decreased survival compared to wild type, whereas sts5S86A-HA had increased survival compared to the sts5-HA control $\left({ }^{* * *} p<0.001\right.$; One-Way ANOVA with Tukey's test). (C) In the sts5S86A-3xYFP mutant, the number of Sts5 granules were increased at temperatures in which the sts5-3xYFP control did not form granules. (D) Quantification from results obtained in C. There is a statistically significant increase in average puncta per cell for the sts5S86A-3xYFP strain as compared to the control for cells incubated between $25^{\circ} \mathrm{C}$ and $35.5^{\circ} \mathrm{C}\left(\mathrm{N}=60\right.$ cells/strain, ${ }^{* * *} \mathrm{p}<0.001,{ }^{* *} \mathrm{p}<0.01,{ }^{*} p<0.05$; One-Way ANOVA with Tukey's test). (E) Wild-type and orb6-as2 strains were cultured in the presence $(+T)$ or absence of thiamine, heat shocked, and plated for CFUs $/ \mathrm{mL}$. Inhibition of Orb6 results in a 17-fold increase in survival as compared to the untreated control $\left({ }^{* * *} p<0.001\right.$; One-Way ANOVA with Tukey's test). 
A Favorable Growth Conditions

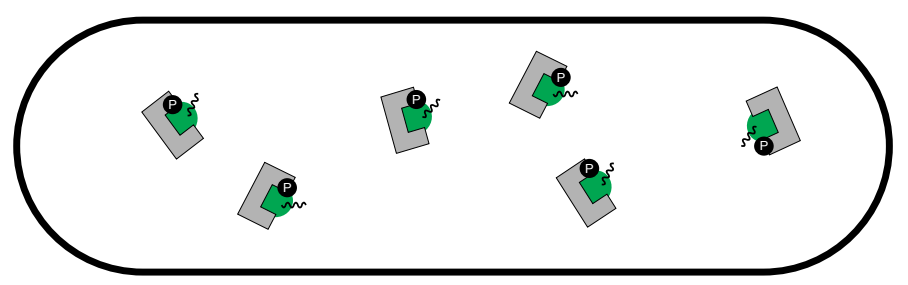

Little RNP Granule Formation

B Nutrient, Osmotic, Oxidative, or Heat Stress

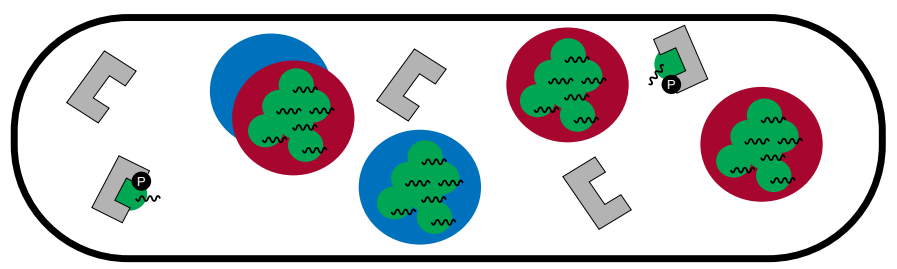

Co-Localization of Sts5 Puncta, P-Bodies, and stress granules

C

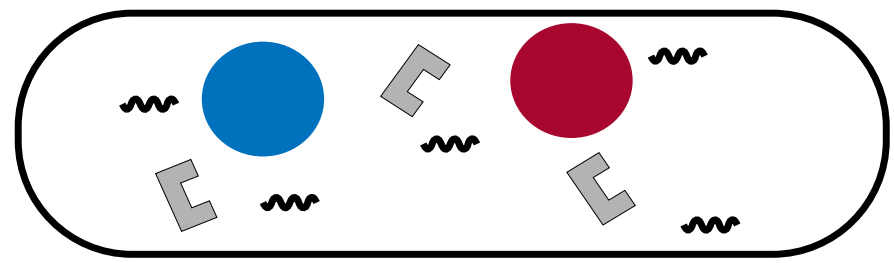

Decreased Heat Tolerance

Decreased Stress Granule Formation After Stress
D

Orb6 Inhibition or Sts5S86A

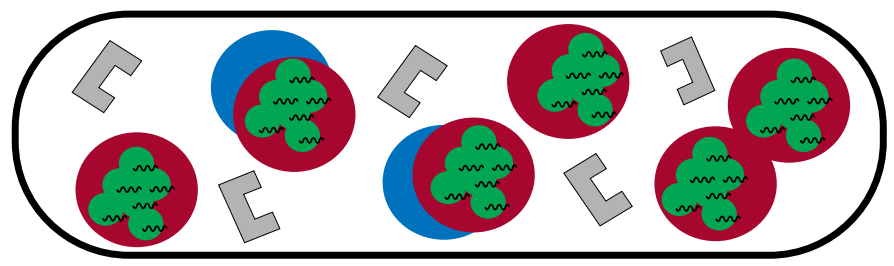

Increased Resilience to Heat

Increased Stress Granule Formation After Stress

Increased Sts5 Coalescence

Legend:

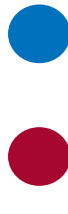

P-Body

Stress Granule
Sts5

Coalesced Sts5 $\sim \sim$ Sts5 Associated mRNA
P Phosphorylation

$\operatorname{Rad} 24$

Figure 5. Model for Sts5 activation and response to stress. (A) Under optimal growth conditions, the RNA binding protein Sts 5 is phosphorylated by the NDR kinase Orb6. This results in binding of Sts 5 to the 14-3-3 protein Rad24 and promotes translation of Sts 5 bound mRNA. Under these conditions, there is little to no formation of RNP granules. (B) Following exposure to heat stress, oxidative stress, osmotic stress, or nutrient starvation, Sts5 coalesces into cytoplasmic puncta which partially co-localize with P-Bodies and stress granules. (C) Loss of Sts5 decreases the formation of stress granules, and cells are less tolerant to heat stress. (D) Inhibition of Orb6 drastically increases resilience to heat stress and promotes the formation of stress granules after heat stress. The sts5S86A mutant exhibits increased Sts 5 coalescence and is more resilient to heat stress. 


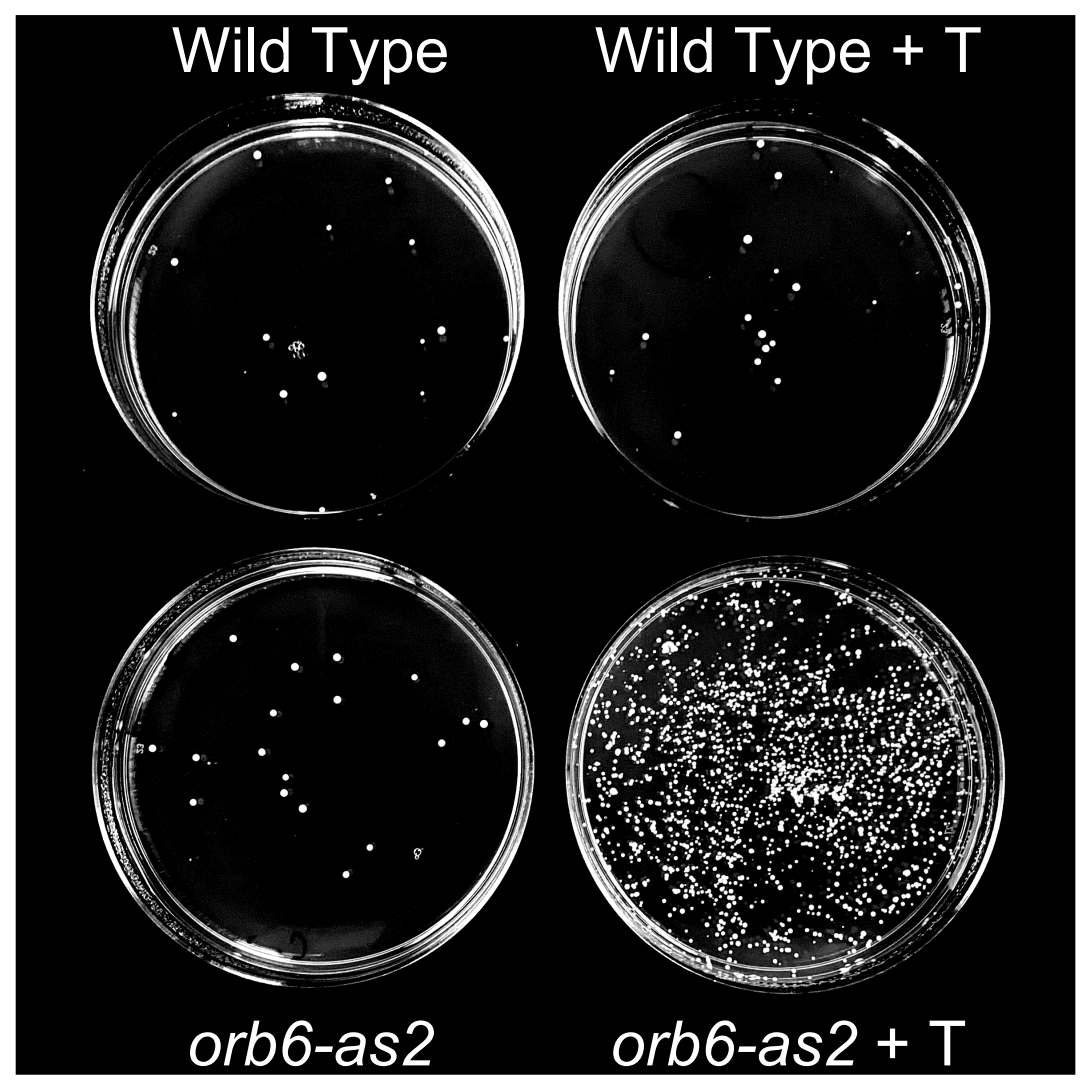

Supplemental Figure 1. Representative image of the orb6-as2 heat shock assay $\left(10^{-2}\right.$ dilution) from the heat shocked sample set. Inhibition of Orb6 drastically increases survival (bottom right) after exposure to a $48^{\circ} \mathrm{C}$ heat shock for 15 minutes, as compared to untreated or wild-type controls. 
Supplemental Table 1: S. pombe strains used in this study.

\begin{tabular}{|c|c|c|}
\hline Strain & Genotype & Source \\
\hline =V1684 & pabp1-DsRed::KanMX6 & (Nilsson and Sunnerhagen, 2011) \\
\hline$=\mathrm{V} 2267$ & sts5-3xGFP::NatMX6 dcp1-mCherry::hph & (Nuñez et al., 2016) \\
\hline$=\mathrm{V} 2361$ & sts5-3xGFP::NatMX6 pabp1-DsRed::KanMX6 & This Study. \\
\hline$=\mathrm{V} 2518$ & sts5 $::$ NatMX6 sts5-HA::KanMX6 & (Chen et al., 2019) \\
\hline$=\mathrm{V} 2522$ & sts54::NatMX6 sts586A-HA::KanMX6 & (Chen et al., 2019) \\
\hline$=\vee 2527$ & orb6 $4:: u r a 4+p J K 148 o r b 6-a s 2:: l e u 1+$ & (Chen et al., 2019) \\
\hline$=\mathrm{V} 2530$ & Wild Type, PN972 & (Leupold, 1949) \\
\hline$=V 2644$ & Wild Type, PN975 & (Leupold, 1949) \\
\hline$=\mathrm{V} 2645$ & sts5 $\because:$ NatMX6 sts5-HA::KanMX6 & (Chen et al., 2019) \\
\hline$=\mathrm{V} 2649$ & sts5 $5:: N a t M X 6$ sts5S86A-HA::KanMX6 & (Chen et al., 2019) \\
\hline$=\mathrm{V} 2674$ & sts5 $::$ KanMX6 & (Chen et al., 2019) \\
\hline =V3192 & sts5 $\Delta::$ NatMX6 pabp1-DsRed::KanMX6 & This Study. \\
\hline =V3226 & orb6 $4:: u r a 4+$ pjk148orb6-as2::leu1+ pabp1-DsRed::KanMX6 & This Study. \\
\hline
\end{tabular}

